OPEN ACCESS

Edited by:

Fabio Martinelli,

Istituto Nazionale dei Tumori (IRCCS),

Italy

Reviewed by:

Benedetta Guani,

Centre Hospitalier Universitaire

Vaudois (CHUV), Switzerland

Giulio Sozzi,

University of Palermo, Italy

*Correspondence:

Jianliu Wang

wangijanliu@pkuph.edu.cn

Specialty section:

This article was submitted to

Gynecological Oncology,

a section of the journal

Frontiers in Oncology

Received: 28 April 2021 Accepted: 01 June 2021

Published: 29 June 2021

Citation:

Zhai L, Zhang $X$, Cui $M$ and Wang J (2021) Sentinel Lymph

Node Mapping in Endometrial Cancer: A Comprehensive Review.

Front. Oncol. 11:701758.

doi: 10.3389/fonc.2021.701758

\section{Sentinel Lymph Node Mapping in Endometrial Cancer: A Comprehensive Review}

\author{
Lirong Zhai ${ }^{1}$, Xiwen Zhang ${ }^{2}$, Manhua Cui ${ }^{2}$ and Jianliu Wang ${ }^{1 *}$ \\ 1 Department of Gynecology and Obstetrics, Peking University People's Hospital, Beijing, China, ${ }^{2}$ Department of Gynecology \\ and Obstetrics, The Second Hospital of Jilin University, Changchun, China
}

Endometrial cancer (EC) is known as a common gynecological malignancy. The incidence rate is on the increase annually. Lymph node status plays a crucial role in evaluating the prognosis and selecting adjuvant therapy. Currently, the patients with high-risk (not comply with any of the following: (1) well-differentiated or moderately differentiated, pathological grade G1 or G2; (2) myometrial invasion< 1/2; (3) tumor diameter $<2 \mathrm{~cm}$ are commonly recommended for a systematic lymphadenectomy (LAD). However, conventional LAD shows high complication incidence and uncertain survival benefits. Sentinel lymph node (SLN) refers to the first lymph node that is passed by the lymphatic metastasis of the primary malignant tumor through the regional lymphatic drainage pathway and can indicate the involvement of lymph nodes across the drainage area. Mounting evidence has demonstrated a high detection rate (DR), sensitivity, and negative predictive value (NPV) in patients with early-stage lower risk EC using sentinel lymph node mapping (SLNM) with pathologic ultra-staging. Meanwhile, SLNM did not compromise the patient's progression-free survival (PFS) and overall survival (OS) with low operative complications. However, the application of SLNM in early-stage high-risk EC patients remains controversial. As revealed by the recent studies, SLNM may also be feasible, effective, and safe in high-risk patients. This review aims at making a systematic description of the progress made in the application of SLNM in the treatment of EC and the relevant controversies, including the application of SLNM in high-risk patients.

\section{Keywords: sentinel lymph node, endometrial cancer, lymphadenectomy, low-volume metastases, high risk, sentinel} lymph node biopsy, sentinel lymph node mapping

\section{INTRODUCTION}

Endometrial cancer (EC) is known as a common female genital malignancy with rapidly increasing incidence these years. In 2021, there will be an estimated 66,570 new cases and 12,940 deaths, making uterine cancer the second most prevalent cancer in women in U.S. after breast cancer (1). Surgery is the mainstay for treatment include total hysterectomy + bilateral salpingooophorectomy + pelvic lymphadenectomy $+/$ - para-aortic lymphadenectomy (TH+BSO+PLAD+/-PALAD). LAD represents a significant component of comprehensive staging for patients with EC. However, studies have revealed that LAD may not be conducive to the prognosis of EC patients $(2,3)$. Besides, the 
selective lymphadenectomy (SLAD) based on "Mayo criteria" shows a high sensitivity with a low specificity (4), and $80 \%$ of the high-risk patients undergo excessive lymph node dissection (5). Additionally, lymph node resection brings a series of complications like vascular nerve injury, lymphedema, lymphatic cysts, and so on (6). Therefore, SLNM or sentinel lymph node biopsy (SLNB) can be effective in addressing this drawback. SLNM does not compromise patient outcome by providing enough information on lymph node directing adjuvant therapy (7), meanwhile, it improves the quality of life by shortening operation time and reducing complications (8). This review is to give a comprehensive view of the application of SLNM in EC, thus providing further choices regarding the lymph node dissection.

\section{DISPUTES ABOUT LAD FOR EC}

The I-IV staging system of EC was initiated in 1962 and transferred from clinical staging to surgical pathologic staging in 1988 (9). Furthermore, staging protocol was re-edited in 2009 for setting IIIC1 as positive pelvic lymph nodes, while IIIC2 refers to the positive para-aortic lymph nodes (10). LAD is an essential part of staging surgery for it provides the lymph node information thus indicating adjuvant therapy, evaluating prognosis, and acting as a therapeutic role. Patients with pelvic or para-aortic lymph node metastasis has dramatically decreased survival rate (10). Additionally, it is believed that LAD eliminates not only existing metastases but also occult or potential metastasis (11). Large retrospective studies showed that LAD is associated with prolonged survival outcome, especially in highrisk EC (12).

However, the therapeutic role and survival benefit of LAD have been in controversial in recent years with the publication of a series of high-quality research. Two large randomized controlled clinical trials (RCT) in 2008 and 2009 included 514 and 1408 patients with EC found no statistical significance in PFS and OS between LAD or not $(13,14)$. Though the two studies are blamed for varying design defects, such as LAD group, did not perform PALAD, the two groups of high-risk patients were not balanced, the proportion of low-risk patients was larger, and adjuvant therapy was not standardized, but it did arouse intensive debates (15). A more recent multicenter study performed by Bougherara et al. (3) demonstrated that LAD brings no survival benefits in intermediate-risk EC group and Zhang et al. (16) analyzed SEER databases and found that after balancing mixing factors, LAD has no survival difference for patients in clinical stage IA with any histologic grade. Besides, LAD increased the incidence of intraoperative complications (prolonged operation time, excessive bleeding, vascular nerve injury, etc.) and post-operative complications (lymphedema, lymphocyst, intestinal obstruction, deep venous thrombosis), thus affecting the quality of life for patients (17). Beesley et al. (18) followed up 643 EC patients and found that the incidence of lymphedema was related to the number of lymph nodes removed, the risk climbed to 50\% when cutting more than 15 lymph nodes. Volpi et al. pointed out that LAD and PALAD are independent risk for lymphedema and lymphocele (6).

At present, the most commonly used strategy is "SLAD" according to "Mayo Criteria" proposed by Mariani et al. (19) in 2000. That is to say, LAD could be omitted in low-risk group (meet all of the following conditions: (1) endometroid type, grade G1 or G2; (2) myometrial invasion $<1 / 2$; and (3) tumor diameter $<2 \mathrm{~cm}$ ), while LAD should be applied in high-risk group (not in accordance with any of the above). However, evidence has confirmed the ability of the method to identify patients with low risk $(1 \%-2.4 \%)$ or high risk $[11.4 \%-19 \%(5,20$, 21 )] with a high sensitivity of $90 \%$, which remains the most sensitive method in determining which patients can be omitted from LAD (22), while the specificity is only $36 \%$ (4). Nearly $80 \%$ of the high-risk group without metastases undergo LAD. In addition, the criteria depend on intraoperative frozen section (FS) and the coincidence rate with postoperative pathology declines when the histology grade and myometrial invasion degree increases, which result in approximately $18 \%$ of EC patients up-staged when final pathologic reports come $(23,24)$.

Therefore, the emergence of SLNM provides an alternative for both systemic LAD and SLAD. Not only does it reduce complications and improve the quality of life of patients, it provides sufficient staging information for evaluating prognosis and guiding adjuvant therapy. Most importantly, it seems not to compromise the survival outcomes of EC patients.

\section{THE CONCEPT AND ORIGIN OF SLN}

SLN refers to one or several lymph nodes that first receive lymphatic fluid from an organ or regional tissue, or the first lymph node that is impacted by the lymphatic metastasis of the primary malignant tumor through the regional lymphatic drainage pathway, thus indicating the involvement of the whole drainage area (25). Theoretically, if SLN is negative, lymphatic metastasis of the drainage area does not occur yet, thus avoiding LAD with following surgical trauma (11). If SLN is found positive in FS, the LAD can be performed directly during the operation. If the H\&E staining and/or ultra-staging of SLN is positive after surgery, patients can either choose adjuvant therapy or a second operation. It is noted that FS of SLN is not a routine in many institutions due to its cost and inaccuracy in finding low volume metastatic disease (LVMD) $(10,26)$, while some send corpus uterine for FS assessment when SLN map failure occurs (27), which is also mentioned in the latest NCCN guideline.

In 1960, Gould et al. first discovered and defined SLN in parotid carcinoma (28). In 1977, Cabanas first used SLN lymphangiography in penile cancer (29). SLNM gradually became a routine procedure for the treatment of breast cancer and skin melanoma. Burke was the first to perform SLNM on 15 patients with EC back in 1996 (30). In the most recent decade, SLN has developed rapidly in EC and has been applied to the treatment of gynecological tumors such as vulvar cancer, cervical 
cancer, and EC. By resecting two to four high-quality lymph nodes, SLNM may have the same diagnostic advantages as LAD and minimize surgical injuries.

\section{THE TECHNIQUE ADVANCES OF SLNM}

\section{Detection Method}

At the present time, SLN detection methods include blue dye method, radionuclide tracing method, indocyanine green (ICG), carbon nanoparticle (CNP), and combination method.

Blue dye method, also known as bioactive dye tracing method, including methylene blue, isosulfur blue, and patent blue. The dye can reach lymphatic vessels and lymph nodes around the tumor, and SLN is the first lymph node to show color. The method features simplicity and cost-effectiveness. However, the blue dye can diffuse to parametrial area thus interfering with the discovery of regional SLN (31). Some methylene blue may leak into the capillaries, resulting in reduced dye volume in lymphatic pathway and decreased SLN DR (32). Also, the risk of allergy cannot be ignored (33).

Radioactive tracers like technetium $(\mathrm{Tc})-99^{\mathrm{m}}$ can remain highly concentrated in the SLN, and emit gamma-rays, which will be detected by gamma detector and single-photon emission computed tomography (SPECT-CT). Radioisotopes can transmit signals through deep tissues. However, the higher cost of detection and imaging equipment, inconvenience, and potential radioactive contamination limit its use (31). The cervical injection site can also stimulate gamma detectors, which makes it difficult to be distinguished from parametrial lymph nodes (34).

ICG fluorescence labeling relies on ICG, a near-infrared fluorescent dye, to drain through lymph nodes and stimulate fluorescence under near-infrared light (700-900 nm) (11) (Figure 1A). It is the most recommended tracer in researches and guidelines, especially for patients with minimally invasive surgery and obesity, due to its highest DR and bilateral detection rate (BDR) (35-37). A randomized non-inferiority trial of 180 patients with uterine and cervical cancer showed that, ICG detected $97 \%$ of the total lymph nodes dissected whereas blue dye identified only $47 \%$ (38). Recent research from Germany compared ICG with blue dye in EC and cervical cancer, as a result, ICG improved the DR (78\% vs. $61 \%, \mathrm{p}=0.006)$ and therefore decreased the LAD rate from $28 \%$ to $9 \%(\mathrm{p}=0.001)$ when mapping failure occurs (39). However, the method relies on near-infrared device (40). Also, ICG enhanced the visualization of lymphatic channels, which leads to an increase in "empty node," which may be compromised by the combination of ICG and Tc-99m (41). Though the adverse reaction rate is extremely low $(0.07 \%$ to $0.5 \%)$ (42), it should be avoided in patients with iodine allergy and liver failure, since it is completely metabolized through liver (10).

CNP suspension derives from carbon nanoparticles with a diameter of $150 \mu \mathrm{m}$ (43). It enters the lymphatic system by macrophage and is excreted through the respiratory and gastrointestinal tract (44). It owns the advantages of unique lymphatic system tendency, small-size, fast diffusion, and longlasting color rendering (43). Meanwhile, it can adsorb anticancer drugs and is difficult to leak out when lymphatic channels are cutoff intraoperatively (43). There are no adverse reactions reported yet, and the DR is quite high. Data from our hospital showed that the combination of CNP and ICG resulted a higher BDR of SLN in cervical and endometrial cancer comparing to CNP or ICG alone $(\mathrm{p}<0.05)(45,46)$.

The combined method is usually a combination of TC-99 and blue dye or ICG. Despite its high DR and low false negative rate (FNR), it is inconvenient and costly.

\section{Injection Route}

Injection routes include cervix and uterine corpus (47).

Cervical injection is the most common and simplest way. It is stable because of the rarity of cervical deformation caused by uterine fibroids, tumor infiltration or conization history (48). Anatomical studies have confirmed that cervical injection can penetrate into uterine vessels, isthmus, parametrial, and uterine body (15), while deep injection can reach para-aortic lymph nodes through pelvic funnel ligament (Figure 1B). The DR of pelvic SLN is higher using cervical injection as confirmed by large-scale studies (more than 100 patients), with a rate over $80 \%$ normally (49). However, the possibility of missing occult paraaortic lymph nodes (PAL) remains disputable. This may be compensated by rare incidence, ranging from $0.5 \%$ to $3.8 \%$ $(47,50,51)$, of isolated para-aortic lymph node (IPL) metastasis, which is negative pelvic lymph node with positive PAL. Also, patients with any site lymph node metastases will receive adjuvant therapy, which theoretically eliminates potential metastatic lesions in para-aortic region (24). In brief, the main protocol for cervical injection is superficial injection $(1-3 \mathrm{~mm})$ with deep injection (1-2 cm or 3-4 cm) at 3- and 9-o'clock, or 3-, 6-, 9-, and 12- o'clock 2-, 4-, 8- and 10-o'clock points $(48,52)$ (Figure 1C).

Uterine corpus injection includes hysteroscopic or transvaginal ultrasound-guided peritumoral (subendometrial) injection (53) preoperatively and subserosal or myometrial injection intraoperatively. Hysteroscopic way can visualize the tumor directly and reflect the real lymphatic metastatic pathway, thus it seems a better method for the evaluation of para-aortic area. The DR ranged from $73 \%$ to $100 \%$, the DR of PAL ranged between $13 \%$ and $56 \%$, and the DR of IPL ranged from $3.4 \%$ to 20\% (54-56). A multicenter RCT showed that hysteroscopic injection has a higher rate in identifying PAL (29\% vs. 19.5, $\mathrm{p}=0.18)$ and IPL $(5.8 \%$ vs. $0 \%)$ than cervical injection; however, there is no statistical difference (57). A recent retrospective analysis of 221 patients undergone hysteroscopic injection resulted in a $94.1 \%, 62.5 \%$, and $2.7 \% \mathrm{DR}, \mathrm{BDR}$, and IPL DR, which contributed to an $88.5 \%$ sensitivity and $96.5 \%$ NPV (58). However, the technique is complicated and not suitable for tumors with large size. Besides, the potential risk of tumor spreading through fallopian tubes is under concern (59). However, the risk of tubal leakage can be avoided by lower intrauterine pressure $(<40 \mathrm{~mm} \mathrm{Hg})$ when performing hysteroscope and even tubal leakage may not result in tumor dissemination (60). The hysteroscopic way is usually injected 
A

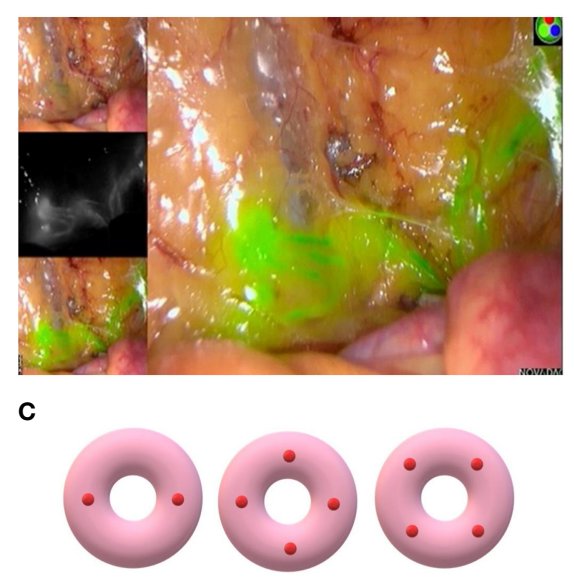

B

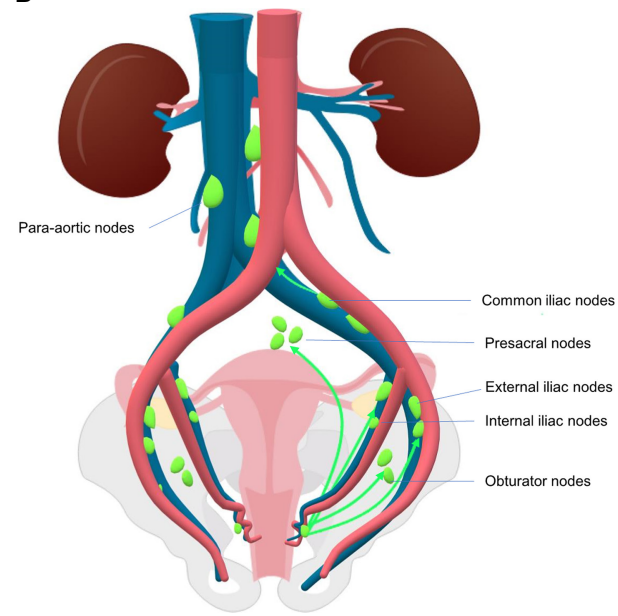

FIGURE 1 | (A) SLN and lymphatic vessel mapped in surgery using ICG dye (Liaoning Pharmaceutical Co., Ltd.) and intraoperative fluorescence imaging system (PC9000, Novadaq Technologies Inc.). (B) Common lymphatic drainage pathway of endometrial cancer. SLNs are mostly located in external iliac and obturator region and less commonly in presacral and common iliac area. (C) Three patterns of cervical injection sites of SLNM: two sides or four quadrants.

around the tumor with $111 \mathrm{MBq}$ Tc $99 \mathrm{~m}$ or $8 \mathrm{ml}$ blue dye $(60)$. Though subserosal injection at fundus is relatively easy, it remains difficult to show the parametrial lymphatic drainage, and most early ECs do not invade or penetrate to the serosa layer. Moreover, patients with uterine fibroids may cause uterine deformation, which made it difficult to inject. The reporting DR of subserosal injection varies from $73 \%$ to $95 \%$ (49). The injection site is generally at the midpoint of the uterine fundus, anterior wall, and posterior wall. Cervical isthmus and peritumoral regions can also be injected.

Overall, Cormier et al. conducted a systematic review of cervical injection in 1,102 cases and corpus injection in 300 cases, which led to a conclusion that the overall DR of cervical injection ranged from $62 \%$ to $100 \%$, corpus injection varied from $73 \%$ to $95 \%$ (49), and the DR of PAL was $39 \%, 17 \%$, and $2 \%$, respectively, in fundus, deep cervix, and superficial cervix injection (49). Cervical injection is simpler, faster, and more effective, which is accepted and recognized as mandatory by worldwide gyn-oncologist in latest consensus and surgical assessment tool of SLNM in EC. It is noted that, in the consensus, cervical injection is obligatory, whereas hysteroscopic or myometrial injection is not suggested. Also, it recommends the utilization of ICG, although blue dye and Tc-99m are available (61).

\section{THE DIAGNOSTIC ACCURACY OF SLNM}

\section{Key Concepts}

DR (49) refers to the percentage of patients with at least one SLN detected of all the patients tested. BDR refers to the proportion of patients with at least one SLN detected in each pelvic cavity to all the patients tested. False negative rate (FNR) refers to the proportion of patients with negative SLN but non-SLN positive to the total number of patients with SLN metastasis. Sensitivity is defined as the proportion of patients with positive SLN to the total number of patients with metastasis. NPV refers to the proportion of patients with SLN-negative and confirmed that no other lymph node metastasis to the total number of patients with SLN-negative. SLNM is supposed to show high sensitivity and low FNR.

\section{SLNM Shows Good Feasibility and Accuracy}

The diagnostic value of SLNM requires the institution to perform LAD after SLNM and do pathologic evaluation of the lymph nodes resected by SLNM and LAD, respectively, to determine the abovementioned indicators. Researches have demonstrated high DR, sensitivity, and NPV in patients with early-stage EC using SLNM with pathologic ultra-staging. SLNM + LAD was performed in 125 patients with FIGO stage I-II EC by SENTIENDO multicenter research (62). The DR was $88.8 \%$. The sensitivity, FNR, and NPV was $84 \%, 2.4 \%$, and $97 \%$, respectively. To improve the sensitivity and NPV, MSKCC proposed that, unilateral or bilateral LAD should be added if SLN map failure occurs in one side or both sides, all suspicious enlarged lymph nodes and peritoneal lesions should be removed, and ultra-staging pathology should be performed after operation. It is called MSKCC algorithm and is recommended in NCCN guideline. In a retrospective study involving 498 patients performed by Barlin et al. (63), the DR was $81 \%$. After the SLN algorithm was applied, the FNR declined sharply from $14.9 \%$ to $1.9 \%$, the sensitivity increased from $85.1 \%$ to $98.1 \%$, and the NPV increased from $98.1 \%$ to $99.8 \%$. When the MSKCC algorithm was retrospectively applied to 14 studies including SENTI-ENDO, NPV increased from 95\% to $99.2 \%$ (47). The FIRES study (64) included 385 patients with EC from 19 surgeons in 10 institutions. The DR and BDR was $86 \%$ and 
52\%. The sensitivity, NPV and FNR was $97.2 \%, 99.6 \%$, and $2.8 \%$. However, these studies are mostly retrospective or prospective in nature, and there are no RCT yet.

The diagnostic value of SLN is thoroughly evaluated in several meta-analysis and systematic reviews, with the DR of SLN ranging from $80 \%$ to $100 \%$, FNR varied between $0 \%$ and $15 \%$, and sensitivity ranged from 86 to $100 \%$. The meta-analysis of 26 studies performed by Kang et al. (65) indicated that the DR and sensitivity was $78 \%$ and $93 \%$, respectively. When learning curve deviation was considered, the DR and sensitivity with less than 30 patients were $82 \%$ and $88 \%$, and those with more than 30 patients were $78 \%$ and $93 \%$, respectively. Cormier et al. (49) conducted a systematic review of 17 studies, with the studies fewer than 30 patients excluded. The DR varied from $60 \%$ to $100 \%$, and the DR exceeded $80 \%$ in subgroup of over 100 patients. After retrospective application of SLN algorithm, the sensitivity, NPV, and FNR was 95\%, 99\%, and 5\% respectively. These results prove that surgeon experience and standard surgical procedures are favorable in improving diagnostic accuracy of SLN. Bodurtha et al. (66) published a metaanalysis of 4,915 patients in 55 studies. The DR and BDR was $81 \%$ and $50 \%$. DR of PAL was $17 \%$. The sensitivity and NPV was $96 \%$ and $99.7 \%$, respectively. ICG and cervical injection could increase the DR $(\mathrm{p}<0.05)$. The similar results were reached by Lin et al. (67) that ICG, cervical injection, and robotic-assisted surgery may improve the DR and sensitivity. While in a recent meta-analysis published by How et al. (68), with 5,348 patients and 48 studies included, the DR, BDR, and PAL DR was $87 \%$, $61 \%$, and $6 \%$, respectively. It is noted that the study showed that SLNM failed to impair the diagnostic value in high-risk histology types, and compared with LAD, SLNM failed to affect survival outcome or increase recurrence risk.

\section{Factors Associated With Diagnostic Value Surgeon Experience}

Plenty of studies have demonstrated the learning curve effect. The accumulation of surgeon experience is associated with an increase in DR and sensitivity. Khoury et al. (69) compared the DR in early (2005-2007) and late (2008-2009) periods of MSKCC, which revealed an increase from $78 \%$ to $94 \%$, suggested that the experience of more than 30 cases played an important role. Also, researchers from University of North Carolina finds 40 cases as a plateau of the learning curve for successful SLN mapping (70).

\section{Tracer Type and Injection Site}

ICG and cervical injection has gained worldwide acceptance for its ability in detecting SLN with a relatively high sensitivity. However, some researchers are working on combination dyes or special injection methods to improve the DR of both pelvic and para-aortic area and compromise the drawback of single method. Cabrera suggested adding Tc-99m to ICG for the increased BDR (69\% vs. $41 \%, \mathrm{p}=0.012)$ and decreased empty node rate $(0 \% v s$. $4 \%, \mathrm{p}=0.032$ ), which is known as a disadvantage to ICG alone (41). Our work shows an increased BDR in identifying SLNs when adding CNP to ICG comparing with CNP or ICG alone
(45). Cervical reinjection when mapping failure occurs has been demonstrated as a feasible strategy to increase the DR and BDR of $\operatorname{SLNM}(71,72)$. Eoh et al. (73) and Ruiz et al. (74) carried out "two-step method", which was a combination of fundus injection and cervical injection of ICG, showing a relatively high DR in both pelvic and para-aortic regions. The overall DR of pelvic SLN and para-aortic SLN was $92.79 \%$ to $100 \%$, and $86 \%$, respectively. The sensitivity, specificity, and NPV ranged from $94.44 \%$ to $100 \%$. Torne et al. developed transvaginal ultrasound-guided myometrial injection of radiotracer (TUMIR), presenting an 82.1\% DR, 92.3\% sensitivity, and 97.7\% NPV (53).

\section{Patient's Condition}

Age, obesity (BMI > 40), pelvic anatomical abnormality (vascular tortuosity), pelvic adhesions (history of operation and radiotherapy), and lymphatic vessel obstruction or destruction (tumor metastasis, deep myometrial infiltration, and endometrial inflammation), all could impact the DR of $\operatorname{SLN}(32,37)$.

\section{Pathology Examination}

Some scholars believe that routine HE staining is possible to miss LVMD in SLN, which could be identified by immunohistochemistry staining (IHC) and serial section, also known as ultra-staging, which is discussed in later paragraphs.

\section{Other Factors}

At present, lymph vascular space invasion (LVSI), nonendometroid histology is seen as independent risk factors for failed mapping (75). The false negative SLN was more likely to appear in unilateral mapping failure patient. Higher SLN detection rate is also reported to be associated with tumor size and patient age, as well as tracer volume (76). However, the role of tumor size, depth of myometrial invasion, pathological type and grade, operation time, and scope, as well as LVSI are still lacking strong evidence. The other factor includes the surgical approach, like robotic or laparoscopic procedure. Cela et al reported 23 patients who underwent robotic-assisted surgery showing a 78.26\% DR and 60.9\% BDR (77). While, Chaowawanit et al summarized 76 patients with laparoscopic surgery and 33 patients with robotic approach. The result showed that laparoscopic procedure was superior than robotic in DR $(97 \%$ vs. $83 \%, \mathrm{p}=0.046)$ and $\mathrm{BDR}(88 \%$ vs. $73 \%)$, whereas the two groups showed similar SLN detection and dissect time (78).

\section{THE THERAPEUTIC SAFETY OF SLNM}

Whether SLNM alone affects the long-term prognosis of patients with EC has been of great concern. Studies have been carried out to compare the oncologic outcome of SLNM-only vs. LAD without SLNM, or SLNM only vs. SLNM+LAD, or SLNM+ LAD vs. LAD group, suggesting that SLNM failed to compromise survival outcome. Even though SLNM resects only a few lymph nodes, the overall DR of metastatic lesions in SLNM group is higher than regular LAD (79), which benefit accurate staging, thus guiding adjuvant therapy. In addition, 
SLNM can improve the quality of life for patients by minimizing operation complications $(7,8)$.

\section{SLNM Detected More Metastases Thus Facilitate Adjuvant Therapy}

It is worth noting that even though SLNM may only remove two to four lymph nodes at a time, with a certain FNR and the risk of missing occult lymph nodes, the overall DR of metastatic lymph nodes is higher compared to conventional LAD (79). Leitao et al. (80) conducted a retrospective study on 507 EC patients. As indicated by the results, LAD rate decreased gradually and the number of removed lymph nodes was in decline accordingly (Y1 20; Y2 10; Y3 7; $\mathrm{p}<0.001)$. However, there was no difference spotted in the detection of cases with lymph node metastasis found every year (Y1 7.0\%, Y2 7.9\%, Y3 7.5\%, p = 1.0), so SLNM failed to reduce the diagnosis of stage IIIC. Despite this, it did reduce the need for LAD and the probability of surgical injury. In addition, Holloway et al. (79) found out that compared with LAD group (661 cases), SLN + LAD group (119 cases) showed a higher DR of metastases $(30.3 \%$ vs. $14.7 \%, \mathrm{p}<0.001)$, more stage IIIC cases $(30.2 \%$ vs. $14.5 \%, \mathrm{p}<0.001)$. SLN was the only metastasis in $50 \%$ of lymph node positive patients, and the FNR was $2.8 \%$. SLN + LAD improved the DR of lymph node metastasis (OR3.29, p < 0.001). Raimond et al. (81) recruited 304 patients, and the incidence of lymph node metastasis in SLN was three times higher than in non-SLN $(16.2 \%$ vs. $5.1 \%, \mathrm{p}=0.03)$. Among SLN positive, $8.1 \%$ were detected by ultra-staging. Furthermore, SLNM exerted no impact on recurrence-free survival (RFS). Buda et al. (82) found out that, in the earlystage patients, the DR of positive pelvic lymph nodes in SLN group (145 patients) was higher than in LAD group (657 patiens) ( $16.7 \%$ vs. $7.3 \% ; \mathrm{p}=0.002)$, including 80 type II EC, and there was no difference observed in 3-year RFS and mortality between the two groups.

The improved detection rate of metastases probably attributes to the application of ultra-staging pathology, which help find previously neglected metastases, and the identification of lymph nodes located outside the routine lymph node dissection area. As revealed by the FIRES studies, $17 \%$ of lymph node-positive patients were found in non-traditional sites (presacral, parametrial areas, and deep iliac) (64). Therefore, the improvement to DR of metastatic lesions may mitigate the false negative consequences of SLN.

\section{SLNM Did Not Impair Survival Outcome}

Although long-term follow-up studies and RCTs for the comparison of survival outcome between SLNM and LAD are lacking, current results showed promising results that SLNM did not compromise the survival prognosis of EC patients (47).

In the SENTI-ENDO study conducted by Darai et al. (83), the outcomes of 125 stage I-II EC patients were assessed. There was no difference observed in recurrence rate $(12.6 \% v$ s. $28.6 \%$; $\mathrm{p}=$ 0.23 ) and RFS between successful SLN detection group and failed group. There was no difference in RFS between lymph node metastasis group and non-metastasis group $(\mathrm{p}=0.23)$. However, the adjuvant therapy in the study was not standardized and it is difficult to validate the accurate survival effect of SLNM. Eriksson et al. (84) applied two lymph node dissection methods to patients with low-risk EC in MSKCC and Mayo Clinic, respectively. MSKCC applied SLN algorithm (642 cases), and Mayo Clinic applied SLAD (493 cases). The results indicated that the DR of metastasis was higher in SLN group. The pelvic lymph node metastasis rate (including LVMD) was 5.1\% and 2.6\% ( $\mathrm{p}=0.03$ ), respectively, while the PAL metastasis rate was $0.8 \%$ and $1.0 \%$ $(\mathrm{p}=0.75)$, respectively. There was no difference in 3 -year diseasefree survival (DFS) $(94.9 \%$ vs. $96.8 \%)$, despite that the adjuvant treatment rate in SLNM group was higher than in SLAD group (27.1\% vs. $10.8 \%$; $\mathrm{p}$ < 0.001). Similar studies have been carried out in two Italian institutions (82) and totally 802 patients with early-stage EC were included. After 30-month median follow-up, there was no difference observed in DFS $(\mathrm{p}=0.396)$ and OS $(\mathrm{p}=0.394)$ between SLNM group and SLAD group. How et al. (85) recruited 275 SLNM + LAD patients and 197 LAD patients for study, which revealed that in clinical stage I patients, there was neither difference in the incidence and type of adjuvant therapy between the two groups, nor difference in RFS. The recurrence rate of pelvic wall in SLNM + LAD group was lower ( $31 \%$ vs. $71 \%)$. The former exhibited a reduced pelvic wall recurrence rate by $68 \%$ (HR $0.32, \mathrm{p}=0.007)$. The authors suggested that SLNM may be superior to LAD due to the removal of lymph nodes at a higher risk of metastasis. However, this study can only prove that SLNM + LAD reduced the recurrence rate compared with LAD alone, for which it can hardly prove the advantages of SLNM alone. Imboden et al. (7) concluded that SLNM offered a considerable balance between oncologic safety and perioperative morbidity in 275 early-stage, G1 or G2 patients, especially for LVSI-positive. As shown in a meta-analysis recently published by Bogani et al. (2), compared with LAD, SLNM exhibited no difference in recurrence rate and PAL metastasis. In addition, A cohort study with 5546 patients published by Polcher et al. (86) indicated that LAD failed to improve DFS or OS compared with SLNM. On the contrary, it resulted in more complications in the high-risk histology type. The most recent multiinstitutional retrospective study performed by Bogani et al. (87) compared the long-term oncologic results of SLNM, SLNM+LAD and LAD. The results found that there was no statistical difference between the three strategies in DFS $(p=0.570)$ and $O S(p=0.911)$; moreover, the survival outcome was similar in low risk, intermediate risk, and high-risk group. Kogan et al (88) compared 193 EC patients with LAD and 250 patients with SLN+LAD. They found that SLN may improve the oncologic outcome with a more favorable 6-year OS (HR 0.5, 95\% CI 0.3-0.8, $\mathrm{p}=0.004$ ) and PFS (HR 0.6, 95\% CI 0.4-0.9, $\mathrm{p}=$ $0.03)$. Also, SLN seemed to reduce the risk of recurrence in pelvis or lymph node region with a 6-year RFS of $95 \%$ compared to 90\% ( $\mathrm{p}=0.04)$ in LAD only group. Recently, Jayot et al. from France analyzed 248 EC patients between 2007 and 2018 undergone SLN procedure, as a result, the 3-year OS was $99 \%$ and 3-year RFS was 92\% (89). 


\section{SLNM Reduced Intraoperative and Postoperative Complications}

The most common complication of LAD was lymphedema, followed by lymph cysts, vascular and nerve injury, blood loss, and prolonged operation, etc. It seems that these risks can be reduced with the application of SLNM. Accorsi et al. (90) found that compared with TH, SLNM did not increases the incidence of intraoperative complications $(\mathrm{p}=1.0)$ and postoperative complications $(\mathrm{p}=0.782)$. While LAD laid more risk on intraoperative complications (HR, 14.25;95\% CI, 1.85-19.63), postoperative complications (HR, 3.11; 95\% CI, 1.62-5.98), and lower-extremity lymph edema (HR, 8.14; 95\% CI, 1.01-65.27). Geppert et al. (91) drew comparison of the perioperative outcomes for $\mathrm{TH}+\mathrm{BSO}, \mathrm{TH}+\mathrm{BSO}+\mathrm{SLN}$, and $\mathrm{TH}+\mathrm{BSO}+$ LAD groups. The average operation time of SLN group and LAD group was found to be extended by 33 and $91 \mathrm{~min}$, respectively. The incidence of lower limb lymphedema in SLN group was significantly lower than in LAD group $(1.3 \%$ vs. $18.1 \%$; $\mathrm{p}=0.0003)$. The same result was shown by Persson et al. $(72$, 92), in which SLNM reduced the risk of lower extremity lymphoedema by 14 times. In addition, Liu et al. (93) found that SLNM group significantly reduced the incidence of postoperative complications $(5.2 \%$ vs. $13 \%$; $\mathrm{p}=0.04)$, decreased intraoperative blood loss (56 $\mathrm{ml}$ vs. $80 \mathrm{ml}$; $\mathrm{p}=0.004$ ), and shortened the operation time (137 min vs. $181 \mathrm{~min}$; $\mathrm{p}<0.0001$ ), meanwhile, the average number of lymph nodes dissected was significantly decreased ( 4 vs. $15 ; \mathrm{p}<0.0001$ ). When comes to lymphedema and lymph cyst, MSKCC concluded that SLN mapping was an independent factor in reducing patient reported lower-extremity lymphedema, while high BMI and adjuvant EBRT were associated with increased lymphedema (94). While another research stated that systemic LAD was the only factor that associated with the presence of lymphocele, the number of dissected nodes showed no impact. Compared with SLN+LAD group, SLN only group significantly decreased lymphocele rate from $14.1 \%$ to $3.4 \%(p=0.009)$ (95). Mayo Clinic analyzed 378 patients and found that SLN may significantly decrease the risk of lymphedema compared with LAD (26.0\% vs. $49.4 \%, \mathrm{p}<0.001)$ (96). Several meta-analyses included current retrospective and prospective studies presented similar conclusions, which was SLN resulted in less blood loss, lymphedema, and other complications, meanwhile, SLN detected more pelvic metastasis $(97,98)$. These results may indicate that SLNM is able to minimize the surgical risk and reduce the complications with no survival detriment in EC, which is of great value to improve the quality of life.

\section{THE APPLICATION OF SLNM IN EARLY- STAGE HIGH-RISK EC}

Nowadays, it is trending to carry on SLNM in early-stage highrisk EC, including high-risk histology (G3 endometroid, serous carcinoma, clear cell carcinoma, and carcinosarcoma), deep myometrial invasion, cervical involvement, and LVSI (+).
Some institutions are making attempt to apply SLNM as routine surgical staging in all EC patients, except for patients with suspected lymph-node metastasis or failed mapping. Previous studies are typically performed on early-stage EC patients with mostly patients with lower-risk of recurrence and fewer higher-risk included. Recent studies attempted to evaluate the diagnostic accuracy and oncologic safety of SLNM in earlystage high-risk patients only. Though there are no RCTs published yet, existing evidence indicates that SLNM may be also efficient and safe in high-risk group, MSKCC has already established SLNM as a routine procedure for all candidate patients, including serous and carcinosarcoma type. However, it is essential to choose appropriate indication and strictly comply with SLN algorithm when using SLNM in high-risk patients (10).

The potential diagnostic value of the SLNM in high-risk patients has been proven in recent years. The DR ranges from $73 \%$ to $100 \%$, the BDR varies from $56 \%$ to $95 \%$, and NPV ranges from $93 \%$ to $100 \%(5,42,53,72,92,99-107)$. Both SENTIENDO study and FIRES studies include low-risk and high-risk EC and present high DR and NPV $(64,83)$. There have been studies only including high-risk patients to evaluate the diagnostic value (Table 1). Frumovitz et al. performed study on 18 high-risk EC patients in 2007. The SLN DR was merely $45 \%$ (108), which may be the result of technique and surgeon experience. Then Torne et al. operated SLNM+LAD+PALAD on 74 high-risk patients in 2013, while the DR, sensitivity, and NPV were $74.3 \%$, 92.3\%, and $97.7 \%$ (53), respectively. Subsequently, in 2015, Farghali et al. showed a 73.1\% DR, 94.4\% sensitivity, and $100 \%$ specificity in 93 high-risk patients (100). In 2016, Ehrisman et al. demonstrated an increase from $92.3 \%$ to $100 \%$ in NPV by applying SLN algorithm to 36 high-risk EC patients (101). In 2017, plenty of constructive research results were obtained. For example, Soliman et al. performed SLNM+LAD+ PALAD under 123 high-risk patients. Nineteen percent of the patients diagnosed with stage III exhibited DR, sensitivity, and FNR of $89 \%$, 95\%, and 4.3\% (103), respectively. Baiocchi et al. included 236 high-risk EC patients. As a result, the SLN arm has a sensitivity of $90 \%$, an NPV of $95.7 \%$, and an FNR of $4.3 \%$. Besides, the positive lymph node DR is significantly increased in SLN group compared with LAD group $(26.7 \%$ vs. $14.3 \%, \mathrm{p}=0.02)$ (106). In the same year, a multi-institutional research was conducted by Touhami et al., who performed SLNM+LAD $+/$-PALAD in 128 high-risk EC patients (including undifferentiated type). They found out that the sensitivity and NPV of SLNM were $95.8 \%$ and 98.2\%, respectively (104). Furthermore, in 2018, Papadia et al. conducted analysis of 42 high-risk patients (including neuroendocrine cancer). They reported that the DR and BDR of SLN were $100 \%$ and $90.5 \%$, respectively. Excitingly, the sensitivity and NPV were both $100 \%$ (42). Sweden teams performed robotic surgery on 257 stage I-II high-risk EC patients, resulting in a sensitivity of $100 \%$ and a NPV of $100 \%$. The BDR was as high as $95 \%$, and no adverse effect occurred (72). Wang et al. recently published their data and found a DR of $86.7 \%$ and FNR, NPV and sensitivity was $11.8 \%$, $97.3 \%$ and $88.2 \%$ respectively. When considering SLN algorithm 
TABLE 1 | The diagnostic value of SLNM in high-risk EC.

\begin{tabular}{|c|c|c|c|c|c|c|c|c|c|c|c|c|c|c|}
\hline Author & $\begin{array}{l}\text { Year of } \\
\text { publish }\end{array}$ & Country & $\begin{array}{l}\text { Study } \\
\text { type }\end{array}$ & $\begin{array}{l}\text { Study } \\
\text { period }\end{array}$ & $\begin{array}{l}\text { Number of } \\
\text { pts }\end{array}$ & Histology & $\begin{array}{l}\text { SLN method (dye } \\
\text { and injection site) }\end{array}$ & $\begin{array}{l}\text { Surgery } \\
\text { approach }\end{array}$ & $\begin{array}{l}\text { Overall } \\
\text { DR }\end{array}$ & BDR & PASDR & Sensitivity & NPV & FNR \\
\hline $\begin{array}{l}\text { Burke et al. } \\
\text { (30) }\end{array}$ & 1996 & USA & pilot & NA & 15 & $\begin{array}{l}\text { EEC(G2,G3), CC, } \\
\text { USC }\end{array}$ & $\begin{array}{l}\text { BD; subserosal, } \\
\text { myometrium }\end{array}$ & Lpt & $67 \%$ & NA & NA & $66.70 \%$ & $87.50 \%$ & $33.30 \%$ \\
\hline $\begin{array}{l}\text { Frumovitz } \\
\text { et al. (108) }\end{array}$ & 2007 & USA & pro & $\begin{array}{l}2002- \\
2004\end{array}$ & 18 & $\begin{array}{l}\mathrm{EEC}(\mathrm{G} 2, \mathrm{G} 3), \mathrm{CC}, \\
\text { USC }\end{array}$ & BD, Tc; Fundus & Lps & $45.00 \%$ & $5.56 \%$ & $22.22 \%$ & NA & NA & NA \\
\hline $\begin{array}{l}\text { Torne et al. } \\
\text { (53) }\end{array}$ & 2013 & Spain & pro & $\begin{array}{l}2006.03- \\
2011.03\end{array}$ & 74 & $\begin{array}{l}\mathrm{EEC}(\mathrm{G} 3), \mathrm{CC}, \mathrm{USC}, \mathrm{DM} \text {, } \\
\mathrm{Cl}\end{array}$ & Tc; TUMIR & Lps & $74.30 \%$ & $14.00 \%$ & $45.40 \%$ & $92.30 \%$ & $97.70 \%$ & $7.70 \%$ \\
\hline $\begin{array}{l}\text { Perissinotti } \\
\text { et al. (99) }\end{array}$ & 2013 & Spain & pro & $\begin{array}{l}2007.06- \\
2010.12\end{array}$ & 44 & $\begin{array}{l}\text { EEC(G3),CC,USC, } \\
\text { USM,DM }\end{array}$ & TC; TUMIR & Lps & $73.00 \%$ & NA & NA & NA & NA & NA \\
\hline $\begin{array}{l}\text { Farghali } \\
\text { et al. (100) }\end{array}$ & 2015 & Egypt & pro & $\begin{array}{l}2007.05 \\
-2011.05\end{array}$ & 93 & $\begin{array}{l}\text { EEC(G2,G3), CC, } \\
\text { USC }\end{array}$ & $\begin{array}{l}\text { BD; subserosal, } \\
\text { myometrium }\end{array}$ & Lpt & $73.10 \%$ & $40.86 \%$ & $0.00 \%$ & $94.40 \%$ & $98.90 \%$ & $5.88 \%$ \\
\hline $\begin{array}{l}\text { Valha et al. } \\
\text { (109) }\end{array}$ & 2015 & Czech & pro & $\begin{array}{l}2012.06- \\
2014.02\end{array}$ & 18 & $\begin{array}{l}\text { stage I-II, intermediate } \\
\text { and high-risk }\end{array}$ & BD; subserosal & Lpt & $88.89 \%$ & NA & $50.00 \%$ & NA & NA & NA \\
\hline $\begin{array}{l}\text { Ehrisman } \\
\text { et al. (101) }\end{array}$ & 2016 & USA & retro & $\begin{array}{l}2012.08- \\
2015.06\end{array}$ & 36 & $\begin{array}{l}\text { EEC(G3),CC,USC, } \\
\text { CSM }\end{array}$ & BD,ICG;cervical & Lps,Rb & $83.00 \%$ & $56.00 \%$ & $3.00 \%$ & $77.80 \%$ & $92.30 \%$ & $22.22 \%$ \\
\hline $\begin{array}{l}\text { Baiocchi } \\
\text { et al. (106) }\end{array}$ & 2017 & Spain & retro & $\begin{array}{l}2007.06- \\
2017.02\end{array}$ & $\begin{array}{l}236(75 \text { SLN } \\
\text { +LAD; } 161 \\
\text { LAD) }\end{array}$ & $\begin{array}{l}\text { EEC(G3),CC,USC, } \\
\text { CSM,DM,LVSI }\end{array}$ & BD; cervical & $\begin{array}{l}\text { Lps, Rb, } \\
\text { Lpt }\end{array}$ & $85.30 \%$ & $60.00 \%$ & $1.50 \%$ & $90.90 \%$ & $95.7 \%$ & $10.00 \%$ \\
\hline $\begin{array}{l}\text { Tanner } \\
\text { et al.J } \\
\text { (110) }\end{array}$ & 2017 & USA & retro & $\begin{array}{l}2012.12- \\
2015.12\end{array}$ & 52 & $\begin{array}{l}\mathrm{EEC}(\mathrm{G} 3), \mathrm{CC}, \mathrm{USC}, \\
\mathrm{CSM}\end{array}$ & BD,ICG;cervical & Lps,Rb & $86.00 \%$ & $59.60 \%$ & $9.00 \%$ & $77.80 \%$ & $94.70 \%$ & $22.20 \%$ \\
\hline $\begin{array}{l}\text { Soliman, } \\
\text { PT (103) }\end{array}$ & 2017 & USA & pro & $\begin{array}{l}2013.04- \\
2016.05\end{array}$ & 101 & $\begin{array}{l}\mathrm{EEC}(\mathrm{G} 3), \mathrm{CC}, \mathrm{USC} \text {, } \\
\mathrm{CSM}, \mathrm{DM}, \mathrm{Cl}\end{array}$ & $\begin{array}{l}\text { ICG, BD, BD+TC; } \\
\text { cervical }\end{array}$ & $\begin{array}{l}\text { Lps, Rb, } \\
\text { Lpt }\end{array}$ & $89.00 \%$ & $58.00 \%$ & $2.00 \%$ & $95.80 \%$ & $98.20 \%$ & $5.00 \%$ \\
\hline $\begin{array}{l}\text { Touhami } \\
\text { et al. (104). }\end{array}$ & 2017 & Canada & retro & $\begin{array}{l}2010.11- \\
2016.11\end{array}$ & 128 & $\begin{array}{l}\mathrm{EEC}(\mathrm{G} 3), \mathrm{CC}, \mathrm{USC}, \\
\mathrm{CSM}, \text { undifferentiated }\end{array}$ & $\begin{array}{l}\mathrm{BD}, \mathrm{TC}, \mathrm{ICG} ; \\
\text { cervical }\end{array}$ & $\begin{array}{l}\text { Lps, Rb, } \\
\text { Lpt }\end{array}$ & $89.80 \%$ & $63.20 \%$ & $5.00 \%$ & $97.43 \%$ & $98.80 \%$ & $2.56 \%$ \\
\hline $\begin{array}{l}\text { Ducie et al. } \\
\text { (107) }\end{array}$ & 2017 & USA & retro & $\begin{array}{l}2006- \\
2013\end{array}$ & 120 & $\begin{array}{l}\text { EEC+any grade+DM; } \\
\text { USC, CC }\end{array}$ & BD, ICG; cervical & NA & NA & NA & NA & $96.40 \%$ & $98.90 \%$ & $3.60 \%$ \\
\hline $\begin{array}{l}\text { Buda et al. } \\
\text { (111) }\end{array}$ & 2018 & $\begin{array}{l}\text { Italy, } \\
\text { Switzerland }\end{array}$ & retro & NA & 171 & $\begin{array}{l}\text { ESMO high- } \\
\text { intermediate and high } \\
\text { risk }\end{array}$ & $\begin{array}{l}\text { ICG, Tc+BD; } \\
\text { cervical }\end{array}$ & NA & $98.00 \%$ & $\begin{array}{l}80.1 \%(\mathrm{ICG}) \\
65.7 \%(\mathrm{BD}, \mathrm{Tc})\end{array}$ & NA & $\begin{array}{l}85.2 \% ; \\
91.2 \% \text { for } \\
\text { algorithm }\end{array}$ & $\begin{array}{l}\text { 93.4\%;96\% for } \\
\text { algorithm }\end{array}$ & $\begin{array}{l}14.7 \% ; 8.8 \% \\
\text { for algorithm }\end{array}$ \\
\hline $\begin{array}{l}\text { Papadia } \\
\text { et al. (42) }\end{array}$ & 2018 & Switzerland & retro & $\begin{array}{l}2012.12- \\
2017.07\end{array}$ & 42 & $\begin{array}{l}\text { EEC(G3),CC,USC, } \\
\text { CSM,NEC }\end{array}$ & ICG; cervical & Lps & $100 \%$ & $90.50 \%$ & NA & $\begin{array}{l}90 \% ; 100 \% \\
\text { for algorithm }\end{array}$ & $\begin{array}{l}\text { 97\%;100\% for } \\
\text { algorithm }\end{array}$ & $\begin{array}{l}10 \% ; 0 \% \text { for } \\
\text { algorithm }\end{array}$ \\
\hline $\begin{array}{l}\text { Persson } \\
\text { et al. (72) }\end{array}$ & 2019 & Sweden & pro & $\begin{array}{l}2014.06- \\
2018.05\end{array}$ & 257 & $\begin{array}{l}\text { EEC(G3),non-EEC, } \\
\text { DM, Cl, non-diploid } \\
\text { cell }\end{array}$ & $\begin{array}{l}\text { ICG; cervical } \\
\text { +/-reinjection }\end{array}$ & $\mathrm{Rb}$ & NA & $\begin{array}{l}82 \% ; 94.8 \% \\
\text { after } \\
\text { reinjection }\end{array}$ & NA & $\begin{array}{l}98 \% ; 100 \% \\
\text { for algorithm }\end{array}$ & $\begin{array}{l}99.5 \% ; 100 \% \\
\text { for algorithm }\end{array}$ & $\begin{array}{l}3.7 \% ; 0 \% \text { for } \\
\text { algorithm }\end{array}$ \\
\hline $\begin{array}{l}\text { Wang et al. } \\
(105)\end{array}$ & 2019 & China & retro & $\begin{array}{l}2016.08- \\
2018.08\end{array}$ & 98 & $\begin{array}{l}\mathrm{EEC}(\mathrm{G} 3), \mathrm{CC}, \mathrm{USC}, \\
\mathrm{CSM}, \mathrm{EEC}(\mathrm{G} 1, \mathrm{G} 2) \\
+\mathrm{DM}, \mathrm{Cl}\end{array}$ & ICG; cervical & NA & $95.92 \%$ & $77.60 \%$ & NA & $\begin{array}{l}88.2 \% \\
90.9 \% \text { for } \\
\text { algorithm }\end{array}$ & $\begin{array}{l}97.47 \% \text {; } \\
\text { 97.30\% for } \\
\text { algorithm }\end{array}$ & $\begin{array}{l}11.8 \% ; 9.1 \% \\
\text { for algorithm }\end{array}$ \\
\hline $\begin{array}{l}\text { Ye et al. } \\
(112)\end{array}$ & 2019 & China & pro & $\begin{array}{l}2016.07- \\
2018.07\end{array}$ & $\begin{array}{l}131 \text { pts with } \\
25 \text { high-risk }\end{array}$ & $\begin{array}{l}\text { EEC(G3),CC,USC, } \\
\text { CSM,undifferentiated }\end{array}$ & ICG; cervical & Lps & $100 \%$ & $72 \%$ & NA & $20 \%$ & $83.30 \%$ & $80 \%$ \\
\hline $\begin{array}{l}\text { Angeles } \\
\text { et al. (76) }\end{array}$ & 2020 & Spain & pro & $\begin{array}{l}2006.03- \\
2017.03\end{array}$ & 123 & $\begin{array}{l}\text { intermediate and high- } \\
\text { risk EC }\end{array}$ & TUMIR & NA & $70.70 \%$ & NA & NA & NA & NA & NA \\
\hline $\begin{array}{l}\text { Taskin } \\
\text { et al. (113) }\end{array}$ & 2020 & Turkey & retro & $\begin{array}{l}2017.05- \\
2018.11\end{array}$ & 38 & $\begin{array}{l}\text { high-risk (Mayo } \\
\text { criteria) }\end{array}$ & ICG; cervical & $\begin{array}{l}\text { Lps, Rb, } \\
\text { Lpt }\end{array}$ & $84.21 \%$ & $68.40 \%$ & NA & $80 \%$ & $93.40 \%$ & NA \\
\hline
\end{tabular}

pts, patients; SLN, sentinel lymph node; LAD, lymphadenectomy; DR, detection rate; BDR, bilateral detection rate; PAS, para-aortic SLN; NPV, negative predictive value; FNR, false negative rate; NA, not applicable; EEC, endometrioid endometrial cancer; G, grade; CC, clear cell carcinoma; USC, uterine serous carcinoma; CSM, carcinosarcoma; DM, deep myometrial invasion; Cl, cervical involvement; BD, blue dye; TC, Technetium-99; TUMIR, transvaginal ultrasoundguided myometrial injection of radiotracer; Lpt, laparotomy; Lps, laparoscopic; Rb, robotic surgery; pro, prospective; retro, retrospective. 
and surgical experience (over 30 cases), the FNR and NPV increased (105). Thus, SLNM seems to be feasible in high-risk context with an acceptable DR and diagnostic value. However, Ye et al analyzed 131 patients using ICG and SLNM followed by LAD (112). The sensitivity and NPV were unexpectedly as low as $20 \%$ and $83.3 \%$, with a surprisingly high FNR of $80 \%$. The author considered the risk of missing IPL of SLNM in high-risk patients may be the reason, a large-scale multicenter study was needed to clarify the result.

Moreover, prospective and retrospective studies indicated that SLNM appears to have no negative impact on oncologic outcomes in high-risk EC patients (Table 2). MSKCC conducted a retrospective analysis of 136 patients with uterine carcinosarcoma in 2016 (114). The result showed that there was no difference in PFS (23 vs. 23.2 months; $\mathrm{p}=0.7$ ) and detection of metastatic lymph nodes $(p=0.2)$ between SLN group and LAD group. Local recurrence rate was $15 \%$ in SLN cohort and $24 \%$ in LAD cohort, which is consistent with previous study conducted by How et al. (85). Subsequently, in 2017, MSKCC retrospectively evaluated 248 patients with uterine serous carcinoma. No difference was observed either in the diagnosis of stage III/IV, adjuvant therapy rate, and 2-year PFS between SLN group and LAD group. However, the incidence of local recurrence was $9.7 \%$ and $9.1 \%$ in SLN group and LAD group (115). The exact effect of SLNM and related adjuvant therapy on local recurrence control needs to be further investigated. The same histology type was further and thoroughly reviewed by MSKCC in a recent paper published by Basaran et al. (118). This time, they carefully categorized uterine serous carcinoma patients in January 1996 to December 31, 2017 into SLN only group (79) and LAD without SLN group (166). The two cohorts showed no survival difference in stage I to III uterine serous carcinoma as they yielded similar detection of nodal metastasis. Also, PALND did not show any survival benefit on OS. Moreover, MSKCC and Mayo Clinic investigated 176 deeply invasive endometrioid EC in 2018. When other factors were balanced, the PFS, OS, and recurrence rate exhibited no difference (117). Additionally, in 2018, Buda et al. reported an Italian multicenter study, which included 266 high-risk patients. The 3-year DFS and OS showed no difference in SLN group and SLAD group (116). In the same year, Buda et al. published data obtained from Italian and Swedish multicenter of 171 high-risk EC patients. The 5-year DFS indicated no difference among SLN group and SLAD group (111). The impact of SLNM on clear cell carcinoma was investigated by Mayo Clinic and MSKCC (119). The researcher included early stage serous or clear cell endometrial carcinoma with any degree of myometrial invasion. The results showed that SLNM cohort (118 patients) did not increase lymphatic recurrence and exhibit a similar OS ( $88 \%$ vs. $77 \%, \mathrm{p}=0.06)$ with LAD cohort (96). However, in node-negative cases, SLNM group may be associated with decreased RFS (73\% vs. 91\%, $\mathrm{p}=0.05)$, despite the majority of SLNM patients received chemotherapy $(84 \%$ vs. $40 \%, \mathrm{p}<0.001)$. Most recently, Bogani et al. compared SLN alone and SLN followed by LAD (121) in 196 highrisk patients (121). The two groups showed no difference in
DFS $(\mathrm{p}=0.416)$ and OS $(\mathrm{p}=0.940)$ despite that LAD removes more positive nodes.

However, it is noted that only a few intuitions perform SLNalgorithm only in the SLN cohort for the comparison study, whereas others are more likely to perform LAD followed by SLNM, thus, the results are rather a comparison between SLN $+\mathrm{LAD}$ and $\mathrm{LAD}$, which make the survival results less convincing and more complicated. The role of backup LAD for high-risk cases remains areas of investigation. Also, there are studies addressing the problem and comparing the oncologic outcomes between SLN and more extensive LAD with or without SLN, preliminary results suggested that there are no difference in these approaches $(87,118)$.

These results may indicate that the application of SLNM in high-risk EC patients is as efficient and safe as in the lower-risk type, for accurate staging, thus guiding adjuvant therapy, suggesting SLN may be an optimal choice for high-risk patients. However, the effect is attributed to the adjuvant therapy based on lymph node status or eradication of lymph node metastases directly is unclear, since earlier studies did show a survival benefit for patients did systemic LAD with an average of 12 lymph nodes moved (122), and the current favorable studies are limited by its prospective or retrospective nature. Lack of RCTs, long-term follow-up studies, standardized SLNM technique, and ultra-staging protocol, as well as adjuvant therapy are the primary concern. In an ideal clinical research, the patients should be randomly assigned into SLNM arm or LAD arm, and receive standard post-operative adjuvant therapy according to stage information (40). It is plausible to add LAD, particularly PALAD, in high-risk group before high-quality evidence is published.

\section{CURRENT APPLICATION OF SLNM}

SLNM is gaining widespread utilization for staging in EC. It was first written in the NCCN guideline since 2014. And for now, FIGO and NCCN all support the utilization of SLNM in apparent uterine-confined EC despite lack of RCTs. Studies have proven that SLNM with ultra-staging may be effective in providing prognostic information for regional lymph node, choosing adjuvant therapy, and reducing operation complications.

NCCN recommends the application of SLNM in EC patients with lesions apparently confined to the uterine cavity without any extra-uterine metastases on imaging examination. Meantime, NCCN also permits the potential use of SLNM in early-stage high-risk EC patients like serous carcinoma, clear cell carcinoma and carcinosarcoma (123). Surgeons must strictly follow the technical details and SLN algorithm in operation, including superficial and deep injection of cervix, thorough evaluation of abdominal and pelvic cavity, resection of all SLN and suspicious enlarged lymph nodes, additional LAD on unmapped side when SLN mapping failure occurs and ultrastaging pathology is performed in combination with routine $\mathrm{H} \& \mathrm{E}$. Whether to perform PALAD is at the discretion of the 
TABLE 2 | The oncologic outcomes of SLNM in high-risk EC.

\begin{tabular}{|c|c|c|c|c|c|c|c|c|c|c|c|c|c|c|}
\hline Author & $\begin{array}{c}\text { Year of } \\
\text { publication }\end{array}$ & Country & $\begin{array}{l}\text { Study } \\
\text { type }\end{array}$ & Time period & $\begin{array}{l}\text { Patient group } \\
\text { (N) }\end{array}$ & Histology & $\begin{array}{l}\text { LN posi- } \\
\text { tive rate }\end{array}$ & $p$ value & DFS & $p$ value & os & $p$ value & $\begin{array}{l}\text { Distant } \\
\text { recurrence rate }\end{array}$ & $p$ value \\
\hline $\begin{array}{l}\text { Schiavone } \\
\text { et al. (114) }\end{array}$ & 2016 & USA & retro & 1998.01-2014.08 & $\begin{array}{l}\text { SLN-A(48) } \\
\text { LAD(88) }\end{array}$ & USM & $\begin{array}{l}22.90 \% \\
21.59 \%\end{array}$ & $\mathrm{p}=0.4$ & $\begin{array}{l}23 \mathrm{~m}(2 \mathrm{y}) \\
23.2 \mathrm{~m}\end{array}$ & $\mathrm{p}=0.7$ & $\begin{array}{l}\text { NA } \\
\text { NA }\end{array}$ & & $70 \%$ & NA \\
\hline $\begin{array}{l}\text { Ducie et al. } \\
\text { (107) }\end{array}$ & 2017 & USA & retro & $\begin{array}{l}\text { SLN (2006-2013) } \\
\text { LAD (2004-2008) }\end{array}$ & $\begin{array}{l}\text { SLN-A(120) } \\
\text { SLAD(103) }\end{array}$ & $\begin{array}{l}\text { EEC: any grade, } \\
\mathrm{Ml}>50 \% \text {; USC/CC, } \\
\text { any MI. }\end{array}$ & $\begin{array}{l}21.70 \% \\
19.40 \%\end{array}$ & $p=0.68$ & $\begin{array}{l}\text { NA } \\
\text { NA }\end{array}$ & & $\begin{array}{l}\text { NA } \\
\text { NA }\end{array}$ & & $\begin{array}{l}\text { NA } \\
\text { NA }\end{array}$ & \\
\hline $\begin{array}{l}\text { Schiavone } \\
\text { et al. (115) }\end{array}$ & 2017 & USA & retro & 2005.01-2015.07 & $\begin{array}{l}\text { SLN-A(153) } \\
\text { LAD(95) }\end{array}$ & USC & $\begin{array}{l}31 \% \\
38 \%\end{array}$ & $\mathrm{p}=0.3$ & $\begin{array}{l}77 \% \\
71 \%\end{array}$ & $p=0.3$ & $\begin{array}{l}\text { NA } \\
\text { NA }\end{array}$ & & $\begin{array}{l}15.03 \% \\
23.16 \%\end{array}$ & NA \\
\hline $\begin{array}{l}\text { Baiocchi } \\
\text { et al. (106) }\end{array}$ & 2017 & Spain & retro & $\begin{array}{l}\text { SLN (2007.06- } \\
2017.02) \\
\text { LAD (2012.11- } \\
2017.02)\end{array}$ & 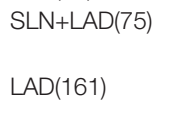 & $\begin{array}{l}\text { EEC(G3), CC, USC, } \\
\text { CSM, DM, LVSI }\end{array}$ & $\begin{array}{l}26.70 \% \\
14.30 \%\end{array}$ & $p=0.02$ & $\begin{array}{l}\text { NA } \\
\text { NA }\end{array}$ & & $\begin{array}{l}\text { NA } \\
\text { NA }\end{array}$ & & $\begin{array}{l}\text { NA } \\
\text { NA }\end{array}$ & \\
\hline $\begin{array}{l}\text { Buda et al. } \\
\text { (111) }\end{array}$ & 2018 & $\begin{array}{l}\text { Italy, } \\
\text { Switzerland }\end{array}$ & retro & NA & $\begin{array}{l}\text { SLN-A(66) } \\
\text { SLN+SLAD } \\
(105)\end{array}$ & $\begin{array}{l}\text { High-intermediate } \\
\text { and high-risk }\end{array}$ & $\begin{array}{l}27.30 \% \\
32.40 \%\end{array}$ & $p=0.297$ & $\begin{array}{l}79.20 \% \\
81.60 \%\end{array}$ & $p=0.831$ & $\begin{array}{l}\text { NA } \\
\text { NA }\end{array}$ & & $\begin{array}{l}0 \\
0.95 \%\end{array}$ & NA \\
\hline $\begin{array}{l}\text { Buda et al. } \\
\text { (116) }\end{array}$ & 2018 & Italy & retro & 2010.10-2014.02 & $\begin{array}{l}\text { SLN(61) } \\
\operatorname{LAD}(139)\end{array}$ & $\begin{array}{l}\text { High-intermediate } \\
\text { and high-risk }\end{array}$ & $\begin{array}{l}16.70 \% \\
7.30 \%\end{array}$ & $p=0.002$ & $\begin{array}{l}\text { HR: } 0.92 \\
\text { (3y) }\end{array}$ & $p=0.646$ & $\begin{array}{l}\text { HR: } 0.92 \\
\text { (3y) }\end{array}$ & $\mathrm{p}=0.675$ & $\begin{array}{l}\text { NA } \\
\text { NA }\end{array}$ & \\
\hline $\begin{array}{l}\text { Schlappe } \\
\text { et al. (117) }\end{array}$ & 2018 & USA & & $\begin{array}{l}\text { SLN (2005-2013) } \\
\text { LND (2004-2008) }\end{array}$ & $\begin{array}{l}\text { SLN-A(82) } \\
\text { LAD(94) }\end{array}$ & DM EEC & $\begin{array}{l}33.30 \% \\
14.80 \%\end{array}$ & $\mathrm{p}=0.005$ & $\begin{array}{l}\text { adjusted } \\
\text { HR:0.87 }\end{array}$ & NA & $\begin{array}{l}\text { adjusted } \\
\text { HR:2.54 }\end{array}$ & NA & $\begin{array}{l}20.80 \% \\
14.90 \%\end{array}$ & NA \\
\hline $\begin{array}{l}\text { Basaran et al. } \\
\text { (118) }\end{array}$ & 2020 & USA & retro & 1996.01-2017.12 & $\begin{array}{l}\text { SLN alone(79) } \\
\text { LND without } \\
\text { SLN (166) }\end{array}$ & USC & $\begin{array}{l}26.50 \% \\
29.50 \%\end{array}$ & $p=0.6$ & $\begin{array}{l}58.8 \%(2 y) \\
64.9 \%(2 y)\end{array}$ & $p=0.478$ & $\begin{array}{l}89.1 \%(2 y) \\
83.9 \%(2 y)\end{array}$ & $\mathrm{p}=0.9$ & $\begin{array}{l}36.7 \% * \\
40.9 \% *\end{array}$ & $p=0.524$ \\
\hline $\begin{array}{l}\text { Schlappe } \\
\text { et al. (119) }\end{array}$ & 2020 & USA & retro & $\begin{array}{l}2006-2013 \\
2004-2008\end{array}$ & $\begin{array}{l}\text { SLN(118) } \\
\text { LND(96) }\end{array}$ & USC/CC with any Ml & $\begin{array}{l}21.70 \% \\
20.50 \%\end{array}$ & $\mathrm{p}=0.83$ & $\begin{array}{l}68.9 \%(3 y) \\
80.3 \%(3 y)\end{array}$ & $p=0.32$ & $\begin{array}{l}87.9 \%(3 y) \\
76.8 \%(3 y)\end{array}$ & $p=0.06$ & NA & \\
\hline $\begin{array}{l}\text { Nasioudis } \\
\text { et al. (120) }\end{array}$ & 2020 & USA & retro & $2012-2015$ & $\begin{array}{l}\text { SLN(460) } \\
\operatorname{LND}(920)\end{array}$ & $\mathrm{EEC}(\mathrm{G} 3)$ and non-EEC & $\begin{array}{c}10.5 \% \\
13.30 \%\end{array}$ & $\begin{array}{l}p=0.10 \\
N A\end{array}$ & $\begin{array}{l}\text { NA } \\
\text { NA }\end{array}$ & & $\begin{array}{l}84.3 \%(3 y) \\
86.8 \%(3 y)\end{array}$ & $\mathrm{p}=0.86$ & NA & \\
\hline $\begin{array}{l}\text { Bagoni et al. } \\
\text { (121) }\end{array}$ & 2021 & Italy & retro & 2009.01-2019.12 & $\begin{array}{l}\text { SLN(50) } \\
\text { SLN+LAD } \\
(146)\end{array}$ & $\begin{array}{l}\mathrm{EEC}(\mathrm{G} 3) \text { with } \mathrm{Ml}>50 \% \\
\text { and non-EEC }\end{array}$ & $\begin{array}{c}28 \% \\
23.20 \%\end{array}$ & & $\begin{array}{l}\text { NA } \\
\text { NA }\end{array}$ & $p=0.416$ & NA & $\mathrm{p}=0.940$ & $\begin{array}{l}16 \% \\
12 \%\end{array}$ & 0.413 \\
\hline
\end{tabular}

* The data refers to all types of recurrence.

N, number; LN, lymph node; DFS, disease-free survival; OS, overall survival; pro, prospective; retro, retrospective; SLN-A, SLN-algorithm; LAD, Iymphadenectomy; EEC, endometrioid endometrial cancer; G, grade; CC, clear cell carcinoma;

USC, uterine serous carcinoma; CSM, carcinosarcoma; MI, myometrial invasion; DM, deep myometrial invasion; LVSI, Iympho-vascular invasion; $m$, months; $y$, year; NA, not applicable; HR, hazard ratio. 
surgeon (48). While in the latest consensus and surgical assessment tool, which aims to standardize the surgical technique and quality of SLNM in EC, it also recommends cervical injection of ICG, however, when mapping failure occurs, it points out 4 choices: waiting and turning to contralateral side, exploring the uncommon regions like presacral, common iliac or para-aortic area, re-injection of tracer, or performing side specific LAD (61).

Moreover, the application of FS of SLN is in debate due to the low sensitivity, expensive price, and the propensity to neglect LVMD (10, 26). However, Tanner et al. (110) argued that it was plausible to add FS when SLN map failure occurs, which was called "reflux FS", as it could reduce the need for LAD based on uterine factors by decreasing the rate from $18.6 \%$ to $7.1 \%$. Besides, they recommended a direct LAD instead a reflux FS for high-risk EC. Similar results were obtained by Sinno et al. (27) and Altin et al. (124). Thus, NCCN guideline suggests that secondary SLAD may be considered in the cases of failed SLN mapping (125). In addition, Renz et al. (126) from Stanford University and Bellaminutti et al. (127) from Switzerland found that adding intraoperative FS to SLN can find micrometastases with a good accuracy, and NPV, thus, may identify patients who are in need for a systemic LAD for dissecting additional lymph node metastases.

At present, the application of SLNM is gradually expanding, and more than $70 \%$ of patients may be suitable for SLNM (50). Recent surveys from ESGO and SGO confirmed that 50.2\% (128) of European gynecological oncologists and $82.7 \%$ (129) of USA gynecologic oncologists adopted SLN in EC. In low-risk patients, who usually do not have to perform LAD, there are $2.4 \%$ lymph node metastatic potential (5), especially in LVSI positive patients (7). Additionally, LVMD is more likely to occur in low-risk patients (130). SLNM can remove fewer lymph nodes with sufficient staging information supporting adjuvant therapy, and will not cause the possibility of post-operative complications to increase compared with hysterectomy alone (7). In high-risk patients who should undergo LAD, approximately $80 \%(5,107)$ of them do not have lymph node metastasis. Moreover, it is difficult for obese patients and patients with severe internal complications to tolerate LAD. Also, adjuvant therapy can eliminate obscured metastases that are not found in surgery theoretically as supported by many clinical trails (131), which showed that concurrent chemoradiotherapy can significantly extend PFS and OS in advanced EC patients. Moreover, SLNM improves the detection of metastases by identifying LVMD with assistance of ultra-staging and identifying lymph nodes in nonregular region, which is significant for accurate staging and choosing adjuvant therapy. Despite lack of RCTs and longterm follow-up studies, existing evidence advocate the utilization of SLNM in uterine-confined EC even in high-risk histology because of sufficient detection rate of SLN and nodal metastases, and similar survival outcome compared with conventional LAD. It is worth expecting long-term survival outcome, cost-performance, and complication incidence of SLNM in early-stage EC patients in ongoing randomized clinical trials.

\section{CONTROVERSIAL ISSUES}

\section{Pathological Ultra-Staging and LVMD}

Pathological assessment methods for lymph nodes include H\&E and IHC staining. Ultra-staging is a combination of serial section and IHC (anti keratin AE1:AE3) to identify the LVMD (10, 15, 66). The standard set by SGO about LVMD is based on breast cancer guidelines published by AJCC (132): macro-metastasis (> $2 \mathrm{~mm}$ ); low-volume metastases (LVM), including micrometastasis (MM) $(0.2-2 \mathrm{~mm})$ and isolated tumor cells (ITCs) $(<0.2 \mathrm{~mm})$. AJCC (133) set term pN0 (i+) for ITCs and pN1mi for MM in breast cancer. In NCCN guideline, $\mathrm{pN} 0$ (i+) is set for ITCs in EC patients (125). A more accurate staging may be needed to guide further personalized adjuvant therapy and evaluate prognosis.

There is no standardized protocol for ultra-staging yet. MSKCC (134) divides H\&E-negative SLN into two levels (50 $\mu \mathrm{m}$ apart). Then, if the previous one remains H\&E negative, two consecutive 5- $\mu \mathrm{m}$ thick sections are sliced at every level, one for $\mathrm{H} \& \mathrm{E}$ and the other for IHC (Figure 2A). M.D. Anderson Cancer Center (135) cut three serial 250- $\mu$ m-thick sections for lymph node which has a negative $\mathrm{H} \& \mathrm{E}$, with one repeating $\mathrm{H} \& \mathrm{E}$. If it is still negative, the other two slices undergo IHC (Figure 2B). As indicated by reports, there is no difference between two kinds ultra-staging on the detection of SLN metastases for both highrisk and low-risk EC patients $(26,136)$.

The incidence of LVMD varies approximately from $3.8 \%$ to $19.7 \%(10,62,79,130,134,137,138)$ However, the LVMD
A

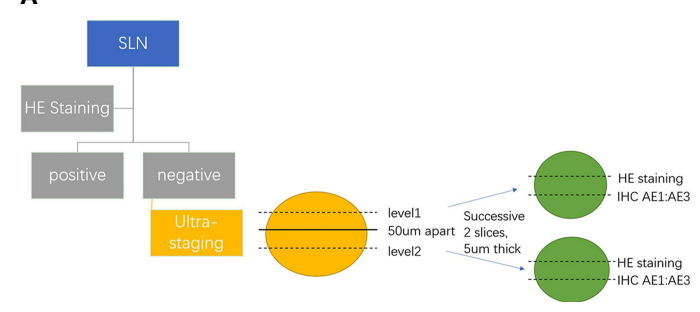

B

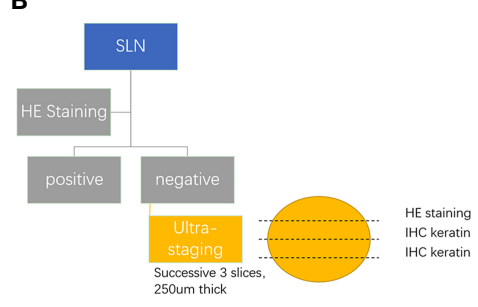

FIGURE 2 | (A) MSKCC SLN ultra-staging protocol. (B) M.D. Anderson Cancer Center SLN ultra-staging protocol. 
detected by ultra-staging accounts for almost $50 \%$ of all lymph node metastases. The risk factors related with LVMD are LVSI, unfavorable histology, myometrial invasion, and so on. Yabushita et al. (139) figured out the relevance between LVSI and the positive expression of keratin in IHC staining. The author stated that keratin positive is the independent risk factor for recurrence. Todo et al analyzed 61 EC patients with intermediate risk for recurrence (140). The results showed a $14.8 \%$ incidence of LVMD and deep myometrial invasion was significantly associated with ITC/MM ( $\mathrm{p}=0.028)$. Bogoni et al. (130) hold that LVMD is more likely to be detected in low-risk patients. However, research done by Mueller et al. concluded that ITC incidence increased with depth of myoinvasion. Twenty-five percent of deeply invasive G1/G2 and 18\% of deeply invasive G3 tumors had ITCs compared to a rate lower than $1 \%$ in noninvasive endometroid EC patients. When coming to noninvasive serous type, the incidence for ITC goes up to 10\% (141).

Though the clinical significance of LVMD remains under investigation, more stage IIIc patients are diagnosed by ultrastaging and $5 \%$ to $15 \%$ patients face upstaging (134). Whether MM or ITC need adjuvant therapy and indicate better or worse prognosis are conflicting. Recent data tend to consider patients with MM for a following adjuvant therapy, whereas patients with ITCs do not. Todo et al. (140) concluded that LVMD was an independent risk factor for extra-pelvic recurrence. Compared to node-negative patients, a noticeable $20 \%$ decrease was observed in 8-year OS and PFS in LVMD patients. However, no statistical difference was calculated. MSKCC (142) reported a large cohort study that $5.2 \%$ patients had LVMD and $5.6 \%$ patients found macrometastases. As a result, the LVMD group shows a significant increase in 3 year-RFS compared with the macrometastases group ( 86 vs. $71 \%, \mathrm{p}<0.001$ ), as most LVMD receive adjuvant therapy. Plante et al. (143) published a single center prospective study involving 519 EC patients. The 3-year PFS was 95.5\% for ITCs, which was similar to MM (85.5\%) and lymph node negative $(87.6 \%)$ and much better than macro-metastases (58.5\%). Brugger et al. (50) found out that patients with ITC and MM received more adjuvant therapy and presented much better oncologic outcomes. A recent review published by Bogani et al. believed that the patients with MM detected in SLN should receive adjuvant therapy, whereas whether ITC undergoes adjuvant therapy depends on uterine factors (130). The similar conclusion was reached by Goebe et al, in which they sent 155 SLN negative patients tissue slides into IHC staining retrospectively (144). Even though $13.5 \%$ of SLN negative patients found ITCs, no recurrence was found in patients had previously undetected ITCs without receiving adjuvant therapy as well, suggesting that ITCs may not be relevant to recurrence risk. However, Sawicki et al. (145) stated that LVMD are independent of histology type, myometrial invasion, LVSI and cervical invasion and they does not affect prognosis. It is noted that in breast cancer, though LVMD is recorded in staging, they do not influence the treatment decision for they do not change survival (126).

In addition, ultra-staging improved the detection of nodal metastasis to two times compared with normal H\&E, and interestingly half of positive lymph nodes are SLN $(79,81)$. SLN may have an advantage in identifying LVMD. Niikura et al. (146) obtained a 5\% of LVMD in SLN, compared to merely $0.3 \%$ in non-SLN. FIRES study (64)also indicated that SLN is more likely to identify metastases than non-SLN (5\% vs. $1 \%$, $\mathrm{p}=0.0001$ ). Moreover, compared with traditional LAD, which removes over 20 lymph nodes, SLNM, which removes less than four lymph nodes in most papers, reduces the workload and makes ultra-staging more feasible for pathologists. SLNM permits a possibility that pathologist could pay attention to fewer lymph nodes. However, it is noted that most institutions only perform ultra-staging on SLN but non-SLN due to many factors, which may underestimate the incidence of LVMD in non-SLN.

Nevertheless, ultra-staging owns such limits, which is timeconsuming, that cannot be done intraoperatively, whereas intraoperative FS seems to be low sensitivity in identifying LVMD and the discrepancy between pathologists and institutions. OSNA, which is one-step nucleic acid amplification, comes to the researchers' eyes. It is a molecular-based method for the detection of metastatic lymph nodes in breast cancer or colorectal cancer patients using CK19 as a single marker. Mounting evidence has demonstrated good sensitivity and specificity of OSNA in identifying positive nodes, especially micro-metastasis, in endometrial cancer (147-150). Compared with ultra-staging, OSNA is much faster thus can be done intraoperatively; moreover, it identified more SLN involvement, resulting in $20.69 \%$ of patients upstaged as FIGO stage III (150). The technique is autonomous and quantifiable, which saves pathologist's work and makes results more comparable and less variable (151). Also, the use of the entire lymph node avoids insufficient analysis of pathology, thus increasing the identification of metastatic lesions. However, one limit is the risk of false-positive cases as CK19 can also be expressed in normal endometrium (152), so developing new specific markers may be necessary. Also, the method needs an entire node which makes morphologic observation of metastatic features unachievable (147), as well as future research for other molecular testing (153). Moreover, the cost is almost 10 times higher than the current pathology examination (147) and the best cutoff value for identifying macro-metastasis and LVMD, as well as predicting non-SLN involvement in EC may need further investigation (154).

\section{Aortic Lymph Node Dissection}

Anatomical study has proven that EC can directly metastasize into PAL through pelvic-infundibular ligament pathway. Currently, the dissection of para-aortic area is left to the surgeon's decision based on NCCN SLN algorithm. The possibility of missing occult PAL metastasis, especially IPL metastasis, is one of the primary concerns of SLNM. But existing evidence shown that the incidence of IPL metastasis is rare with approximately $0.5 \%$ to $3.8 \%(49,51)$. Chiang et al. (155) summarized 18 papers and concluded that the incidence of IPL metastasis is as low as $1.7 \%$. Kumar et al. (21) demonstrated that lymph node metastatic rate for para-aortic region and pelvic cavity is similar (12\% vs. 17\%). When pelvic lymph nodes are 
positive, 51\% have PAL metastases. Whereas when pelvic lymph nodes are negative, PAL metastases, namely IPL metastasis, are found in $3 \%$ patients. Usually, patients with positive pelvic lymph nodes would receive adjuvant therapy, which could eliminate the possible aortic lesions in theory, for SLNM with ultra-staging has an excellent ability to detect pelvic metastasis with high sensitivity and NPV. Also, researchers have developed strategies like "dual site injection (156)" or "reinjection (72)" to increase the detection of aortic SLN to reduce FNR. Researchers from Korea showed that a sequential administration of bilateral uterine cornus injection of ICG followed by cervical injection, improved the para-aortic SLN detection rate from 5.7\% to $38.2 \%$ in upper para-aortic area $(\mathrm{p}<0.001)$ and $18.7 \%$ to $67.1 \%$ in lower para-aortic area $(\mathrm{p}<0.001)$, which in turn identified more metastatic SLN in aortic area $(7.9 \%$ vs. $2.4 \%)(p=0.070)(157)$. Researchers from Italy and Turkey suggest the addition of preoperative PET-CT in favor of PALAD decision $(111,113$, 158). Taskin included 38 high-risk patients. Though SLN algorithm had a $100 \%$ sensitivity and NPV in finding the pelvic metastases, the IPL metastases were only detected by PET-CT. Risk factors associated with PAL metastases are reported to be type II EC, pelvic lymph node metastases, deep myometrial invasion $(\geq 1 / 2)$ and LVSI, thus, PALAD based on these risk factors may be reasonable choice. It is noted that the detection of metastatic PAL was similar between SLN group and LAD group even in high-risk histology type EC $(106,117)$, which indicates that SLNM does not compromise the detection of PAL metastases in high-risk patients.

Moreover, the survival benefit of PALAD remains controversial. SEPAL study indicated that PALAD failed to affect the prognosis in low-risk patients, despite a positive impact on intermediate and high-risk patients (12); however, CART analysis conducted by Barlin et al. (159) stated that PALAD bears no relation to OS in EC patients. Whether the oncologic outcome is influenced by removing metastases directly or by personalized adjuvant therapy like radiotherapy extent based on lymph node status is unclear. Some believe that PAL metastases may be eradicated by adjuvant therapy dependent on accurate staging, which has shown to be an advantage of SLNM, which was found to detect more stage IIIC patients despite fewer lymph nodes dissected than extensive LAD.

\section{Non-SLN Metastasis}

A major challenge in implementing SLNM lies in the potential of residual metastasis of non-SLN. Retrospective data have reported an incidence of $35 \%$ to $40 \%$ of non-SLN metastasis $(64,138)$. The risk of non-SLN metastasis is associated with the size of SLN metastasis and uterine higher-risk factors (160). Touhami et al. (138) found out that $60.8 \%$ of non-SLNs were positive when SLN was found to harbor macro-metastases. Otherwise, only $5 \%$ nonSLN was positive when SLN had LVMD. Similar results were reached by Biocchi, 54.5\% macrometastasis and $15.4 \%$ micrometastasis were found non-SLN involvement, whereas in patients with ITCs in SLN, no metastasis was found in non-SLN (161). Turkish Gynecologic Oncology Group showed that one third SLN positive had non-SLN metastases, and the ratio increases to two thirds when SLN involvement was macrometastasis (162). Although non-SLN metastases could be controlled by adjuvant therapy and the promising results of high-risk EC patients support the hypothesis, the appropriate management of non-SLN is still worthy of further studies. Therefore, it is essential to strictly follow SLN algorithm, carefully evaluate non-SLN, and remove all suspicious enlarged lymph nodes. Further studies should be carried on to evaluate the effect of leaving metastatic non-SLNs in-situ.

\section{FUTURE DIRECTIONS}

In summary, quantities of studies indicated that SLNM may be a safe and effective alternative for lymph node assessment in apparently uterine-confined EC with a sufficient diagnostic accuracy and similar survival prognosis even in unfavorable histology types, thus it is gaining widespread acceptance to perform SLNM in EC patients. However, the lack of convinced evidence like RCTs and long-term follow-up data limit its utilization. Further investigations should be focused on the oncologic outcomes of SLNM and the clinical relevance of LVMD on adjuvant therapy. Better standardization of SLNM protocol, surgical training program, and ultra-staging technique are also needed. Besides, further improvement in the diagnostic accuracy and therapeutic safety of SLNM are in urgent need to provide more personal and minimal-invasive treatment for EC patients and make a difference to their prognosis.

\section{AUTHOR CONTRIBUTIONS}

LZ drafted the manuscript. LZ was responsible for the planning and carrying out the study. LZ and XZ reviewed the literature and summarized the data. MC carefully revised the manuscript. JW was responsible for the conceptualization and final review of this manuscript. All authors contributed to the article and approved the submitted version.

\section{FUNDING}

This study was supported by the National Natural Science Foundation of China (grants. 81874108, 81802607, and 82072861), the Beijing Municipal Natural Science Foundation (grant 7202213), and National Key Technology R\&D Program of China (grants 2019YFC1005200 and 2019YFC1005204). 


\section{REFERENCES}

1. Siegel RL, Miller KD, Fuchs HE, Jemal A. Cancer Statistics, 2021. CA Cancer J Clin (2021) 71(1):7-33. doi: 10.3322/caac.21654

2. Bogani G, Murgia F, Ditto A, Raspagliesi F. Sentinel Node Mapping vs. Lymphadenectomy in Endometrial Cancer: A Systematic Review and MetaAnalysis. Gynecol Oncol (2019) 153(3):676-83. doi: 10.1016/j.ygyno. 2019.03.254

3. Bougherara L, Azais H, Behal H, Canlorbe G, Ballester M, Bendifallah S, et al. Does Lymphadenectomy Improve Survival in Patients With Intermediate Risk Endometrial Cancer? A Multicentric Study From the FRANCOGYN Research Group. Int J Gynecol Cancer (2019) 29(2):282-9. doi: 10.1136/ijgc-2018-000051

4. Lefringhouse JR, Elder JW, Baldwin LA, Miller RW, DeSimone CP, van Nagell JR Jr, et al. Prospective Validation of an Intraoperative Algorithm to Guide Surgical Staging in Early Endometrial Cancer. Gynecol Oncol (2017) 145(1):50-4. doi: 10.1016/j.ygyno.2017.01.032

5. Cetinkaya K, Atalay F, Bacinoglu A, Dervisoglu H. To What Extent is Risk Grouping Method Successful in Deciding Surgical Staging in Endometrial Cancer? Tumori (2016) 102(4):422-5. doi: 10.5301/tj.5000497

6. Volpi L, Sozzi G, Capozzi VA, Ricco' M, Merisio C, Di Serio M, et al. Long Term Complications Following Pelvic and Para-Aortic Lymphadenectomy for Endometrial Cancer, Incidence and Potential Risk Factors: A Single Institution Experience. Int J Gynecol Cancer (2019) 29(2):312-9. doi: 10.1136/ijgc-2018-000084

7. Imboden S, Mereu L, Siegenthaler F, Pellegrini A, Papadia A, Tateo S, et al. Oncological Safety and Perioperative Morbidity in Low-Risk Endometrial Cancer With Sentinel Lymph-Node Dissection. Eur J Surg Oncol J Eur Soc Surg Oncol Br Assoc Surg Oncol (2019) 45(9):1638-43. doi: 10.1016/ j.ejso.2019.05.026

8. Polan RM, Rossi EC, Barber EL. Extent of Lymphadenectomy and Postoperative Major Complications Among Women With Endometrial Cancer Treated With Minimally Invasive Surgery. Am J Obstet Gynecol (2019) 220(3):263.e1-263.e8. doi: 10.1016/j.ajog.2018.11.1102

9. Rungruang B, Olawaiye AB. Comprehensive Surgical Staging for Endometrial Cancer. Rev Obstet Gynecol (2012) 5(1):28-34

10. Holloway RW, Abu-Rustum NR, Backes FJ, Boggess JF, Gotlieb WH, Jeffrey Lowery W, et al. Sentinel Lymph Node Mapping and Staging in Endometrial Cancer: A Society of Gynecologic Oncology Literature Review With Consensus Recommendations. Gynecol Oncol (2017) 146(2):405-15. doi: 10.1016/j.ygyno.2017.05.027

11. Bogani G, Raspagliesi F, Leone Roberti Maggiore U, Mariani A. Current Landscape and Future Perspective of Sentinel Node Mapping in Endometrial Cancer. J Gynecol Oncol (2018) 29(6):e94. doi: 10.3802/jgo.2018.29.e94

12. Todo Y, Kato H, Kaneuchi M, Watari H, Takeda M, Sakuragi N. Survival Effect of Para-Aortic Lymphadenectomy in Endometrial Cancer (SEPAL Study): A Retrospective Cohort Analysis. Lancet (2010) 375(9721):1165-72. doi: 10.1016/S0140-6736(09)62002-X

13. Benedetti Panici P, Basile S, Maneschi F, Alberto Lissoni A, Signorelli M, Scambia G, et al. Systematic Pelvic Lymphadenectomy vs. No Lymphadenectomy in Early-Stage Endometrial Carcinoma: Randomized Clinical Trial. J Natl Cancer Institute (2008) 100(23):1707-16. doi: 10.1093/jnci/djn397

14. Kitchener H, Swart AM, Qian Q, Amos C, Parmar MK. Efficacy of Systematic Pelvic Lymphadenectomy in Endometrial Cancer (MRC ASTEC Trial): A Randomised Study. Lancet (2009) 373(9658):125-36. doi: 10.1016/S0140-6736(08)61766-3

15. Renee Franklin C, Tanner EJ. 3rd. Where Are We Going With Sentinel Lymph Node Mapping in Gynecologic Cancers? Curr Oncol Rep (2018) 20 (12):96. doi: 10.1007/s11912-018-0744-4

16. Zheng Y, Yang X, Liang Y, Zhang T, Chen J, Li Y, et al. Effects of Lymphadenectomy Among Women With Stage IA Endometrial Cancer: A SEER Database Analysis. Future Oncol (Lond Engl) (2019) 15(19):2251-66. doi: 10.2217/fon-2019-0080

17. Dowdy SC, Borah BJ, Bakkum-Gamez JN, Weaver AL, McGree ME, Haas LR, et al. Prospective Assessment of Survival, Morbidity, and Cost Associated With Lymphadenectomy in Low-Risk Endometrial Cancer. Gynecol Oncol (2012) 127(1):5-10. doi: 10.1016/j.ygyno.2012.06.035
18. Beesley VL, Rowlands IJ, Hayes SC, Janda M, O'Rourke P, Marquart L, et al. Incidence, Risk Factors and Estimates of a Woman's Risk of Developing Secondary Lower Limb Lymphedema and Lymphedema-Specific Supportive Care Needs in Women Treated for Endometrial Cancer. Gynecol Oncol (2015) 136(1):87-93. doi: 10.1016/j.ygyno.2014.11.006

19. Mariani A, Webb MJ, Keeney GL, Haddock MG, Calori G, Podratz KC Low-Risk Corpus Cancer: Is Lymphadenectomy or Radiotherapy Necessary? Am J Obstet Gynecol (2000) 182(6):1506-19. doi: 10.1067/mob.2000.107335

20. AlHilli MM, Podratz KC, Dowdy SC, Bakkum-Gamez JN, Weaver AL, McGree ME, et al. Risk-Scoring System for the Individualized Prediction of Lymphatic Dissemination in Patients With Endometrioid Endometrial Cancer. Gynecol Oncol (2013) 131(1):103-8. doi: 10.1016/j.ygyno. 2013.06.037

21. Kumar S, Podratz KC, Bakkum-Gamez JN, Dowdy SC, Weaver AL, McGree ME, et al . Prospective Assessment of the Prevalence of Pelvic, Paraaortic and High Paraaortic Lymph Node Metastasis in Endometrial Cancer. Gynecol Oncol (2014) 132(1):38-43. doi: 10.1016/j.ygyno.2013.10.002

22. Kilts TP, Glaser GE, Langstraat CL, Kumar A, Weaver AL, Mc Gree ME, et al. Comparing Risk Stratification Criteria for Predicting Lymphatic Dissemination in Endometrial Cancer. Gynecol Oncol (2019) 155(1):21-6. doi: 10.1016/j.ygyno.2019.08.005

23. Frumovitz M, Slomovitz BM, Singh DK, Broaddus RR, Abrams J, Sun CC, et al. Frozen Section Analyses as Predictors of Lymphatic Spread in Patients With Early-Stage Uterine Cancer. J Am Coll Surg (2004) 199(3):388-93. doi: 10.1016/j.jamcollsurg.2004.05.258

24. Brooks RA, Fleming GF, Lastra RR, Lee NK, Moroney JW, Son CH, et al. Current Recommendations and Recent Progress in Endometrial Cancer. $C A$ Cancer J Clin (2019) 69(4):258-79. doi: 10.3322/caac.21561

25. Dogan NU, Dogan S, Favero G, Kohler C, Dursun P. The Basics of Sentinel Lymph Node Biopsy: Anatomical and Pathophysiological Considerations and Clinical Aspects. J Oncol (2019) 2019:3415630. doi: 10.1155/2019/3415630

26. Malpica A, Euscher ED, Hecht JL, Ali-Fehmi R, Quick CM, Singh N, et al. Endometrial Carcinoma, Grossing and Processing Issues: Recommendations of the International Society of Gynecologic Pathologists. Int J Gynecol Pathol (2019) 38(Suppl 1):S9-S24. doi: 10.1097/PGP.0000000000000552

27. Sinno AK, Peijnenburg E, Fader AN, Temkin SM, Stone R, Levinson K, et al. Reducing Overtreatment: A Comparison of Lymph Node Assessment Strategies for Endometrial Cancer. Gynecol Oncol (2016) 143(2):281-6. doi: 10.1016/j.ygyno.2016.08.323

28. Gould EA, Winship T, Philbin PH, Kerr HH. Observations on a "Sentinel Node" in Cancer of the Parotid. Cancer (1960) 13:77-8. doi: 10.1002/10970142(196001/02)13:1<77::aid-cncr2820130114>3.0.co;2-d

29. Cabanas RM. An Approach for the Treatment of Penile Carcinoma. Cancer (1977) 39(2):456-66. doi: 10.1002/1097-0142(197702)39:2<456::aidcncr2820390214>3.0.co;2-i

30. Burke TW, Levenback C, Tornos C, Morris M, Wharton JT, Gershenson DM. Intraabdominal Lymphatic Mapping to Direct Selective Pelvic and Paraaortic Lymphadenectomy in Women With HighRisk Endometrial Cancer: Results of a Pilot Study. Gynecol Oncol (1996) 62:169-73. doi: 10.1006/gyno.1996.0211

31. Du J, Li Y, Wang Q, Batchu N, Zou J, Sun C, et al. Sentinel Lymph Node Mapping in Gynecological Oncology. Oncol Lett (2017) 14(6):7669-75. doi: $10.3892 / \mathrm{ol} .2017 .7219$

32. Eitan R, Sabah G, Krissi H, Raban O, Ben-Haroush A, Goldschmit C, et al. Robotic Blue-Dye Sentinel Lymph Node Detection for Endometrial Cancer Factors Predicting Successful Mapping. Eur J Surg Oncol J Eur Soc Surg Oncol Br Assoc Surg Oncol (2015) 41(12):1659-63. doi: 10.1016/ j.ejso.2015.09.006

33. Bézu C, Coutant C, Salengro A, Daraï E, Rouzier R, Uzan S. Anaphylactic Response to Blue Dye During Sentinel Lymph Node Biopsy. Surg Oncol (2011) 20(1):e55-9. doi: 10.1016/j.suronc.2010.10.002

34. Kraft O, Havel M. Detection of Sentinel Lymph Nodes in Gynecologic Tumours by Planar Scintigraphy and SPECT/CT. Mol Imaging Radionucl Ther (2012) 21(2):47-55. doi: 10.4274/Mirt.236

35. Ruscito I, Gasparri ML, Braicu EI, Bellati F, Raio L, Sehouli J, et al. Sentinel Node Mapping in Cervical and Endometrial Cancer: Indocyanine Green Versus Other Conventional Dyes-a Meta-Analysis. Ann Surg Oncol (2016) 23(11):3749-56. doi: 10.1245/s10434-016-5236-x 
36. Papadia A, Zapardiel I, Bussi B, Ghezzi F, Ceccaroni M, De Ponti E, et al. Sentinel Lymph Node Mapping in Patients With Stage I Endometrial Carcinoma: A Focus on Bilateral Mapping Identification by Comparing Radiotracer Tc99(m) With Blue Dye Versus Indocyanine Green Fluorescent Dye. J Cancer Res Clin Oncol (2017) 143(3):475-80. doi: 10.1007/s00432016-2297-y

37. Eriksson AG, Montovano M, Beavis A, Soslow RA, Zhou Q, Abu-Rustum NR, et al. Impact of Obesity on Sentinel Lymph Node Mapping in Patients With Newly Diagnosed Uterine Cancer Undergoing Robotic Surgery. Ann Surg Oncol (2016) 23(8):2522-8. doi: 10.1245/s10434-016-5134-2

38. Frumovitz M, Plante M, Lee PS, Sandadi S, Lilja JF, Escobar PF, et al. NearInfrared Fluorescence for Detection of Sentinel Lymph Nodes in Women With Cervical and Uterine Cancers (FILM): A Randomised, Phase 3, Multicentre, Non-Inferiority Trial. Lancet Oncol (2018) 19(10):1394-403. doi: 10.1016/S1470-2045(18)30448-0

39. Pölcher M, Matz S, Braun M, Brambs C, Beer M, Hamann M. Sentinel Lymph Node Mapping With Indocyanine Green Compared to Blue Dye Tracer in Gynecologic Malignancies-a Single Center Experience of 218 Patients. J Surg Oncol (2021) 123(4):1092-8. doi: 10.1002/jso.26338

40. Sullivan SA, Rossi EC. Sentinel Lymph Node Biopsy in Endometrial Cancer: A New Standard of Care? Curr Treat Options Oncol (2017) 18(10):62. doi: 10.1007/s11864-017-0503-Z

41. Cabrera S, Bebia V, Franco-Camps S, Forcada C, Villasboas-Rosciolesi D, Navales I, et al. Technetium-99m-indocyanine Green Versus technetium$99 \mathrm{~m}$-methylene Blue for Sentinel Lymph Node Biopsy in Early-Stage Endometrial Cancer. Int J Gynecol Cancer (2020) 30(3):311-7. doi: 10.1136/ijgc-2019-000923

42. Papadia A, Gasparri ML, Radan AP, Stampfli CAL, Rau TT, Mueller MD. Retrospective Validation of the Laparoscopic ICG SLN Mapping in Patients With Grade 3 Endometrial Cancer. J Cancer Res Clin Oncol (2018) 144 (7):1385-93. doi: 10.1007/s00432-018-2648-y

43. Zhang L, Huang Y, Yang C, Zhu T, Lin Y, Gao H, et al. Application of a Carbon Nanoparticle Suspension for Sentinel Lymph Node Mapping in Patients With Early Breast Cancer: A Retrospective Cohort Study. World J Surg Oncol (2018) 16(1):112. doi: 10.1186/s12957-018-1414-6

44. Zuo J, Wu LY, Cheng M, Bai P, Lei CZ, Li N, et al. Comparison Study of Laparoscopic Sentinel Lymph Node Mapping in Endometrial Carcinoma Using Carbon Nanoparticles and Lymphatic Pathway Verification. J Minim Invasive Gynecol (2018) (6):1125-32. doi: 10.1016/j.jmig.2018.11.002

45. Liang SC, Wang ZQ, Wang JL. Clinical Analysis of 76 Cases of Sentinel Lymph Node Detection in Cervical Cancer and Endometrial Cancer. Zhonghua Fu Chan Ke Za Zhi (2017) 52(9):605-11. doi: 10.3760/ cma.j.issn.0529-567X.2017.09.006

46. Hou H, Dai Y, Liang S, Wang Z, Wang J. Sentinel Lymph Node Biopsy is Feasible in Cervical Cancer Laparoscopic Surgery: A Single-Center Retrospective Cohort Study. J Oncol (2021) 2021:5510623. doi: 10.1155/ 2021/5510623

47. Tschernichovsky R, Diver EJ, Schorge JO, Goodman A. The Role of Lymphadenectomy Versus Sentinel Lymph Node Biopsy in Early-stage Endometrial Cancer: A Review of the Literature. Am J Clin Oncol (2016) 39(5):516-21. doi: 10.1097/COC.0000000000000302

48. Abu-Rustum NR. Sentinel Lymph Node Mapping for Endometrial Cancer: A Modern Approach to Surgical Staging. J Natl Compr Cancer Network (2014) 12(2):288-97. doi: 10.6004/jnccn.2014.0026

49. Cormier B, Rozenholc AT, Gotlieb W, Plante M, Giede C. Communities of Practice Group of Society of Gynecologic Oncology of C. Sentinel Lymph Node Procedure in Endometrial Cancer: A Systematic Review and Proposal for Standardization of Future Research. Gynecol Oncol (2015) 138(2):47885. doi: 10.1016/j.ygyno.2015.05.039

50. Brugger S, Hamann M, Mosner M, Beer M, Braun M, Polcher M. Endometrial Cancer-How Many Patients Could Benefit From Sentinel Lymph Node Dissection? World J Surg Oncol (2018) 16(1):95. doi: 10.1186/s12957-018-1392-8

51. Abu-Rustum NR, Gomez JD, Alektiar KM, Soslow RA, Hensley ML, Leitao MM Jr, et al. The Incidence of Isolated Paraaortic Nodal Metastasis in Surgically Staged Endometrial Cancer Patients With Negative Pelvic Lymph Nodes. Gynecol Oncol (2009) 115(2):236-8. doi: 10.1016/j.ygyno. 2009.07.016
52. Abu-Rustum NR. Sentinel Lymph Node Mapping for Endometrial Cancer: A Modern Approach to Surgical Staging. J Natl Compr Cancer Network JNCCN (2014) 12(2):288-97. doi: 10.6004/jnccn.2014.0026

53. Torné A, Pahisa J, Vidal-Sicart S, Martínez-Roman S, Paredes P, Puerto B, et al. Transvaginal Ultrasound-Guided Myometrial Injection of Radiotracer (TUMIR): A New Method for Sentinel Lymph Node Detection in Endometrial Cancer. Gynecol Oncol (2013) 128(1):88-94. doi: 10.1016/ j.ygyno.2012.10.008

54. Niikura H, Kaiho-Sakuma M, Tokunaga H, Toyoshima M, Utsunomiya H, Nagase S, et al. Tracer Injection Sites and Combinations for Sentinel Lymph Node Detection in Patients With Endometrial Cancer. Gynecol Oncol (2013) 131(2):299-303. doi: 10.1016/j.ygyno.2013.08.018

55. Favero G, Pfiffer T, Ribeiro A, Carvalho JP, Baracat EC, Mechsner S, et al. Laparoscopic Sentinel Lymph Node Detection After Hysteroscopic Injection of technetium-99 in Patients With Endometrial Cancer. Int J Gynecol Cancer (2015) 25(3):423-30. doi: 10.1097/IGC.0000000000000387

56. Solima E, Martinelli F, Ditto A, Maccauro M, Carcangiu M, Mariani L, et al. Diagnostic Accuracy of Sentinel Node in Endometrial Cancer by Using Hysteroscopic Injection of Radiolabeled Tracer. Gynecol Oncol (2012) 126 (3):419-23. doi: 10.1016/j.ygyno.2012.05.025

57. Ditto A, Casarin J, Pinelli C, Perrone AM, Scollo P, Martinelli F, et al. Hysteroscopic Versus Cervical Injection for Sentinel Node Detection in Endometrial Cancer: A Multicenter Prospective Randomised Controlled Trial From the Multicenter Italian Trials in Ovarian Cancer (MITO) Study Group. Eur J Cancer (2020) 140:1-10. doi: 10.1016/j.ejca.2020.08.030

58. Martinelli F, Ditto A, Bogani G, Leone Roberti Maggiore U, Signorelli M, Chiappa V, et al. Sentinel Lymph Node Mapping in Endometrial Cancer: Performance of Hysteroscopic Injection of Tracers. Int J Gynecol Cancer (2020) 30(3):332-8. doi: 10.1136/ijgc-2019-000930

59. Perrone AM, Casadio P, Formelli G, Levorato M, Ghi T, Costa S, et al. Cervical and Hysteroscopic Injection for Identification of Sentinel Lymph Node in Endometrial Cancer. Gynecol Oncol (2008) 111(1):62-7. doi: 10.1016/j.ygyno.2008.05.032

60. Solima E, Brusati V, Ditto A, Kusamura S, Martinelli F, Hanozet F, et al. Hysteroscopy in Endometrial Cancer: New Methods to Evaluate Transtubal Leakage of Saline Distension Medium. Am J Obstet Gynecol (2008) 198 (2):214 e211-214. doi: 10.1016/j.ajog.2007.07.035

61. Moloney K, Janda M, Frumovitz M, Leitao M, Abu-Rustum NR, Rossi E, et al. Development of a Surgical Competency Assessment Tool for Sentinel Lymph Node Dissection by Minimally Invasive Surgery for Endometrial Cancer. Int J Gynecol Cancer (2021) 31(5):647-55. doi: 10.1136/ijgc-2020002315

62. Ballester M, Dubernard G, Lécuru F, Heitz D, Mathevet P. Detection Rate and Diagnostic Accuracy of Sentinel-Node Biopsy in Early Stage Endometrial Cancer: A Prospective Multicentre Study (SENTI-ENDO). Lancet Oncol (2011) 12:469-76. doi: 10.1016/S1470-2045(11)70070-5

63. Barlin JN, Khoury-Collado F, Kim CH, Leitao MM Jr, Chi DS, Sonoda Y, et al. The Importance of Applying a Sentinel Lymph Node Mapping Algorithm in Endometrial Cancer Staging: Beyond Removal of Blue Nodes. Gynecol Oncol (2012) 125(3):531-5. doi: 10.1016/j.ygyno. 2012.02.021

64. Rossi EC, Kowalski LD, Scalici J, Cantrell L, Schuler K, Hanna RK, et al. A Comparison of Sentinel Lymph Node Biopsy to Lymphadenectomy for Endometrial Cancer Staging (FIRES Trial): A Multicentre, Prospective, Cohort Study. Lancet Oncol (2017) 18(3):384-92. doi: 10.1016/S1470-2045 (17)30068-2

65. Kang S, Yoo HJ, Hwang JH, Lim MC, Seo SS, Park SY. Sentinel Lymph Node Biopsy in Endometrial Cancer: Meta-Analysis of 26 Studies. Gynecol Oncol (2011) 123(3):522-7. doi: 10.1016/j.ygyno.2011.08.034

66. Bodurtha Smith AJ, Fader AN, Tanner EJ. Sentinel Lymph Node Assessment in Endometrial Cancer: A Systematic Review and Meta-Analysis. Am J Obstet Gynecol (2017) 216(5):459-476 e410. doi: 10.1016/j.ajog.2016.11.1033

67. Lin H, Ding Z, Kota VG, Zhang X, Zhou J. Sentinel Lymph Node Mapping in Endometrial Cancer: A Systematic Review and Meta-Analysis. Oncotarget (2017) 8(28):46601-10. doi: 10.18632/oncotarget.16662

68. How JA, O'Farrell P, Amajoud Z, Lau S, Salvador S, How E, et al. Sentinel Lymph Node Mapping in Endometrial Cancer: A Systematic Review and 
Meta-Analysis. Minerva Ginecologica (2018) 70(2):194. doi: 10.23736/ S0026-4784.17.04179-X

69. Khoury-Collado F, Glaser GE, Zivanovic O, Sonoda Y, Levine DA, Chi DS, et al. Improving Sentinel Lymph Node Detection Rates in Endometrial Cancer: How Many Cases Are Needed? Gynecol Oncol (2009) 115(3):453-5. doi: 10.1016/j.ygyno.2009.08.026

70. Tucker K, Staley SA, Gehrig PA, Soper JT, Boggess JF, Ivanova A, et al. Defining the Learning Curve for Successful Staging With Sentinel Lymph Node Biopsy for Endometrial Cancer Among Surgeons At an Academic Institution. Int J Gynecol Cancer (2020) 30(3):346-51. doi: 10.1136/ijgc2019-000942

71. Capozzi VA, Valentina C, Giulio S, Alessandra C, Giulia G, Giulia A, et al. Sentinel Node Mapping in Endometrial Cancer: Tips and Tricks to Improve Bilateral Detection Rate. The Sentitricks Study, a Monocentric Experience. Taiwanese J Obstet Gynecol (2021) 60(1):31-5. doi: 10.1016/j.tjog. 2020.11 .006

72. Persson J, Salehi S, Bollino M, Lonnerfors C, Falconer H, Geppert B. Pelvic Sentinel Lymph Node Detection in High-Risk Endometrial Cancer (SHRECTrial)-the Final Step Towards a Paradigm Shift in Surgical Staging. Eur J Cancer (2019) 116:77-85. doi: 10.1016/j.ejca.2019.04.025

73. Eoh KJ, Lee YJ, Kim HS, Lee JY, Nam EJ, Kim S, et al. Two-Step Sentinel Lymph Node Mapping Strategy in Endometrial Cancer Staging Using Fluorescent Imaging: A Novel Sentinel Lymph Node Tracer Injection Procedure. Surg Oncol (2018) 27(3):514-9. doi: 10.1016/j.suronc. 2018.07.001

74. Ruiz R, Gorostidi M, Jaunarena I, Goiri C, Aguerre J, Lekuona A. Both RISK Sentinel Node Biopsy in Endometrial Cancer With Dual Cervical and Fundal Indocyanine Green Injection. Int J Gynecol Cancer (2018) 28(1):139-44. doi: 10.1097/IGC.0000000000001151

75. Sozzi G, Fanfani F, Berretta R, Capozzi VA, Uccella S, Buono N, et al. Laparoscopic Sentinel Node Mapping With Intracervical Indocyanine Green Injection for Endometrial Cancer: The SENTIFAIL Study - A Multicentric Analysis of Predictors of Failed Mapping. Int J Gynecol Cancer (2020) 30 (11):1713-8. doi: 10.1136/ijgc-2020-001724

76. Angeles MA, Migliorelli F, León Ramírez LF, Ros C, Perissinotti A, Tapias A, et al. Predictive Factors of Preoperative Sentinel Lymph Node Detection in Intermediate and High-Risk Endometrial Cancer. Q J Nucl Med Mol Imaging (2020) doi: 10.23736/S1824-4785.20.03246-X.

77. Cela V, Sergiampietri C, Rosa Obino ME, Bifulco G, Giovanni Artini P, Papini F. Sentinel-Lymph-Node Mapping With Indocyanine Green in Robotic-Assisted Laparoscopic Surgery for Early Endometrial Cancer: A Retrospective Analysis. Facts Views Vis Obgyn (2020) 11(4):323-28.

78. Chaowawanit W, Campbell V, Wilson E, Chetty N, Perrin L, Jagasia N, et al. Comparison Between Laparoscopic and Robotic Surgery for Sentinel Lymph Node Mapping in Endometrial Cancer Using Indocyanine Green and Near Infra-Red Fluorescence Imaging. J Obstet Gynaecol (2020), 1-5. doi: 10.1080/ 01443615.2020 .1789953

79. Holloway RW, Gupta S, Stavitzski NM, Zhu X, Takimoto EL, Gubbi A, et al. Sentinel Lymph Node Mapping With Staging Lymphadenectomy for Patients With Endometrial Cancer Increases the Detection of Metastasis. Gynecol Oncol (2016) 141(2):206-10. doi: 10.1016/j.ygyno.2016.02.018

80. Leitao MM Jr., Khoury-Collado F, Gardner G, Sonoda Y, Brown CL, Alektiar KM, et al. Impact of Incorporating an Algorithm That Utilizes Sentinel Lymph Node Mapping During Minimally Invasive Procedures on the Detection of Stage IIIC Endometrial Cancer. Gynecol Oncol (2013) 129 (1):38-41. doi: 10.1016/j.ygyno.2013.01.002

81. Raimond E, Ballester M, Hudry D, Bendifallah S, Daraï E, Graesslin O, et al. Impact of Sentinel Lymph Node Biopsy on the Therapeutic Management of Early-Stage Endometrial Cancer: Results of a Retrospective Multicenter Study. Gynecol Oncol (2014) 133(3):506-11. doi: 10.1016/j.ygyno.2014. 03.019

82. Buda A, Di Martino G, Restaino S, De Ponti E, Monterossi G, Giuliani D, et al. The Impact on Survival of Two Different Staging Strategies in Apparent Early Stage Endometrial Cancer Comparing Sentinel Lymph Nodes Mapping Algorithm and Selective Lymphadenectomy: An Italian Retrospective Analysis of Two Reference Centers. Gynecol Oncol (2017) 147(3):528-34. doi: 10.1016/j.ygyno.2017.09.033
83. Darai E, Dubernard G, Bats AS, Heitz D, Mathevet P, Marret H, et al. Sentinel Node Biopsy for the Management of Early Stage Endometrial Cancer: Long-Term Results of the SENTI-ENDO Study. Gynecol Oncol (2015) 136(1):54-9. doi: 10.1016/j.ygyno.2014.09.011

84. Zahl Eriksson AG, Ducie J, Ali N, McGree ME, Weaver AL, Bogani G, et al. Comparison of a Sentinel Lymph Node and a Selective Lymphadenectomy Algorithm in Patients With Endometrioid Endometrial Carcinoma and Limited Myometrial Invasion. Gynecol Oncol (2016) 140(3):394-9. doi: 10.1016/j.ygyno.2015.12.028

85. How J, Gauthier C, Abitbol J, Lau S, Salvador S, Gotlieb R, et al. Impact of Sentinel Lymph Node Mapping on Recurrence Patterns in Endometrial Cancer. Gynecol Oncol (2017) 144(3):503-9. doi: 10.1016/j.ygyno.2017.01.013

86. Polcher M, Rottmann M, Brugger S, et al. Lymph Node Dissection in Endometrial Cancer and Clinical Outcome: A Population-Based Study in 5546 Patients. Gynecol Oncol (2019) 154(1):65-71. doi: 10.1016/ j.ygyno.2019.04.002

87. Bogani G, Casarin J, Maggiore ULR, Ditto A, Pinelli C, Dell'acqua A, et al. Survival Outcomes in Endometrial Cancer Patients Having Lymphadenectomy, Sentinel Node Mapping Followed by Lymphadectomy and Sentinel Node Mapping Alone: Long-term Results of a PropensityMatched Analysis. Gynecol Oncol (2020) 158(1):77-83. doi: 10.1016/ j.ygyno.2020.04.691

88. Kogan L, Matanes E, Wissing M, et al. The Added Value of Sentinel Node Mapping in Endometrial Cancer. Gynecol Oncol (2020) 158(1):84-91. doi: 10.1016/j.ygyno.2020.04.687

89. Jayot A, Owen C, Bendifallah S, Kolanska K, Boudy AS, Touboul C, et al. Relevance of Sentinel Lymph Node Biopsy in Early Endometrial Cancer: A Series of 249 Cases. Eur J Obstet gynecol Reprod Biol (2021) 258:208-15. doi: 10.1016/j.ejogrb.2020.12.038

90. Accorsi GS, Paiva LL, Schmidt R, Vieira M, Reis R, Andrade C. Sentinel Lymph Node Mapping vs Systematic Lymphadenectomy for Endometrial Cancer: Surgical Morbidity and Lymphatic Complications. J Minim Invasive Gynecol (2020) 27(4):938-45.e2. doi: 10.1016/j.jmig.2019.07.030

91. Geppert B, Lonnerfors C, Bollino M, Persson J. Sentinel Lymph Node Biopsy in Endometrial Cancer-Feasibility, Safety and Lymphatic Complications. Gynecol Oncol (2018) 148(3):491-8. doi: 10.1016/j.ygyno.2017.12.017

92. Persson J, Geppert B, Lonnerfors C, Bollino M, Masback A. Description of a Reproducible Anatomically Based Surgical Algorithm for Detection of Pelvic Sentinel Lymph Nodes in Endometrial Cancer. Gynecol Oncol (2017) 147 (1):120-5. doi: 10.1016/j.ygyno.2017.07.131

93. Liu CY, Elias KM, Howitt BE, Lee LJ, Feltmate CM. Sentinel Lymph Node Mapping Reduces Practice Pattern Variations in Surgical Staging for Endometrial Adenocarcinoma: A Before and After Study. Gynecol Oncol (2017) 145(2):248-55. doi: 10.1016/j.ygyno.2017.03.012

94. Leitao MM Jr., Zhou QC, Gomez-Hidalgo NR, Iasonos A, Baser R, Mezzancello M, et al. Patient-Reported Outcomes After Surgery for Endometrial Carcinoma: Prevalence of Lower-Extremity Lymphedema After Sentinel Lymph Node Mapping Versus Lymphadenectomy. Gynecol Oncol (2020) 156(1):147-53. doi: 10.1016/j.ygyno.2019.11.003

95. Diniz TP, Drizlionoks E, Faloppa CC, et al. Impact of Sentinel Node Mapping in Decreasing the Risk of Lymphocele in Endometrial Cancer. Ann Surg Oncol (2020). doi: 10.1245/s10434-020-09282-z

96. Glaser G, Dinoi G, Multinu F, Yost K, Al Hilli M, Larish A, et al. Reduced Lymphedema After Sentinel Lymph Node Biopsy Versus Lymphadenectomy for Endometrial Cancer. Int J Gynecol Cancer (2021) 31(1):85-91. doi: 10.1136/ijgc-2020-001924

97. Helgers RJA, Winkens B, Slangen BFM, Werner HMJ. Lymphedema and Post-Operative Complications After Sentinel Lymph Node Biopsy Versus Lymphadenectomy in Endometrial Carcinomas-a Systematic Review and Meta-Analysis. J Clin Med (2020) 10(1):120. doi: 10.3390/jcm10010120

98. Gu Y, Cheng H, Zong L, Kong Y, Xiang Y. Operative and Oncological Outcomes Comparing Sentinel Node Mapping and Systematic Lymphadenectomy in Endometrial Cancer Staging: Meta-Analysis With Trial Sequential Analysis. Front Oncol (2020) 10:580128. doi: 10.3389/ fonc. 2020.580128

99. Perissinotti A, Paredes P, Vidal-Sicart S, Torné A, Albela S, Navales I, et al. Use of SPECT/CT for Improved Sentinel Lymph Node Localization in 
Endometrial Cancer. Gynecol Oncol (2013) 129(1):42-8. doi: 10.1016/ j.ygyno.2013.01.022

100. Farghali MM, Allam IS, Abdelazim IA, El-Kady OS, Rashed AR, Gareer WY, et al. Accuracy of Sentinel Node in Detecting Lymph Node Metastasis in Primary Endometrial Carcinoma. Asian Pacific J Cancer Prev APJCP (2015) 16(15):6691-6. doi: 10.7314/APJCP.2015.16.15.6691

101. Ehrisman J, Secord AA, Berchuck A, Lee PS, Di Santo N, Lopez-Acevedo M, et al. Performance of Sentinel Lymph Node Biopsy in High-Risk Endometrial Cancer. Gynecol Oncol Rep (2016) 17:69-71. doi: 10.1016/j.gore.2016.04.002

102. Tanner EJ, Ojalvo L, Stone RL, Levinson K, Temkin SM, Murdock T, et al. The Utility of Sentinel Lymph Node Mapping in High-Grade Endometrial Cancer. Int J Gynecol Cancer (2017) 27(7):1416-1421. doi: 10.1097/ IGC. 0000000000001047

103. Soliman PT, Westin SN, Dioun S, Sun CC, Euscher E, Munsell MF, et al. A Prospective Validation Study of Sentinel Lymph Node Mapping for HighRisk Endometrial Cancer. Gynecol Oncol (2017) 146(2):234-9. doi: 10.1016/ j.ygyno.2017.05.016

104. Touhami O, Gregoire J, Renaud MC, Sebastianelli A, Plante M. Performance of Sentinel Lymph Node (SLN) Mapping in High-Risk Endometrial Cancer. Gynecol Oncol (2017) 147(3):549-53. doi: 10.1016/j.ygyno.2017.09.014

105. Wang T, Hu Y, He Y, Sun P, Guo Z. A Retrospective Validation Study of Sentinel Lymph Node Mapping for High-Risk Endometrial Cancer. Arch Gynecol Obstet (2019) 299(5):1429-35. doi: 10.1007/s00404-019-05085-0

106. Baiocchi G, Mantoan H, Kumagai LY, Gonçalves BT, Badiglian-Filho L, de Oliveira Menezes AN, et al. The Impact of Sentinel Node-Mapping in Staging High-Risk Endometrial Cancer. Ann Surg Oncol (2017) 24 (13):3981-7. doi: 10.1245/s10434-017-6132-8

107. Ducie JA, Eriksson AGZ, Ali N, McGree ME, Weaver AL, Bogani G, et al. Comparison of a Sentinel Lymph Node Mapping Algorithm and Comprehensive Lymphadenectomy in the Detection of Stage IIIC Endometrial Carcinoma at Higher Risk for Nodal Disease. Gynecol Oncol (2017) 147(3):541-8. doi: 10.1016/j.ygyno.2017.09.030

108. Frumovitz M, Bodurka DC, Broaddus RR, Coleman RL, Sood AK, Gershenson DM, et al. Lymphatic Mapping and Sentinel Node Biopsy in Women With High-Risk Endometrial Cancer. Gynecol Oncol (2007) 104 (1):100-3. doi: 10.1016/j.ygyno.2006.07.033

109. Valha P, Kucera E, Sak P, Stepanek O, Michal M. Intraoperative Subserosal Approach to Label Sentinel Nodes in Intermediate and High-Risk Endometrial Cancer. Eur J Gynaecol Oncol (2015) 36(6):643-6.

110. Tanner E, Puechl A, Levinson K, et al. Use of a Novel Sentinel Lymph Node Mapping Algorithm Reduces the Need for Pelvic Lymphadenectomy in LowGrade Endometrial Cancer. Gynecol Oncol (2017) 147(3):535-40. doi: 10.1016/j.ygyno.2017.10.020

111. Buda A, Gasparri ML, Puppo A, Mereu L, De Ponti E, Di Martino G, et al. Lymph Node Evaluation in High-Risk Early Stage Endometrial Cancer: A Multi-Institutional Retrospective Analysis Comparing the Sentinel Lymph Node (SLN) Algorithm and SLN With Selective Lymphadenectomy. Gynecol Oncol (2018) 150(2):261-6. doi: 10.1016/j.ygyno.2018.06.003

112. Ye L, Li S, Lu W, He Q, Li Y, Li B, et al. A Prospective Study of Sentinel Lymph Node Mapping for Endometrial Cancer: Is It Effective in High-Risk Subtypes? Oncologist (2019) 24(12):e1381-7. doi: 10.1634/theoncologist.2019-0113

113. Taşkin S, Varli B, Ersöz CC, Altin D, Soydal Ç, Ortaç F. Complementary Role of 18F-FDG PET/CT for Sentinel Lymph Node Algorithm in Endometrial Cancer With High-Risk Factors for Lymphatic Metastasis. Nucl Med Commun (2020) 41(4):389-94. doi: 10.1097/MNM.0000000000001157

114. Schiavone MB, Zivanovic O, Zhou Q, Leitao MM Jr, Levine DA, Soslow RA, et al. Survival of Patients With Uterine Carcinosarcoma Undergoing Sentinel Lymph Node Mapping. Ann Surg Oncol (2016) 23(1):196-202. doi: 10.1245/ s10434-015-4612-2

115. Schiavone MB, Scelzo C, Straight C, Zhou Q, Alektiar KM, Makker V, et al. Survival of Patients With Serous Uterine Carcinoma Undergoing Sentinel Lymph Node Mapping. Ann Surg Oncol (2017) 24(7):1965-71. doi: 10.1245/ s10434-017-5816-4

116. Buda A, Restaino S, Di Martino G, De Ponti E, Monterossi G, Dinoi G, et al. The Impact of the Type of Nodal Assessment on Prognosis in Patients With High-Intermediate and High-Risk ESMO/ESGO/ESTRO Group Endometrial Cancer. A Multicenter Italian Study. Eur J Surg Oncol J Eur
Soc Surg Oncol Br Assoc Surg Oncol (2018) 44(10):1562-7. doi: 10.1016/ j.ejso.2018.06.034

117. Schlappe BA, Weaver AL, Ducie JA, Eriksson AGZ, Dowdy SC, Cliby WA, et al. Multicenter Study Comparing Oncologic Outcomes Between Two Nodal Assessment Methods in Patients With Deeply Invasive Endometrioid Endometrial Carcinoma: A Sentinel Lymph Node Algorithm Versus a Comprehensive Pelvic and Paraaortic Lymphadenectomy. Gynecol Oncol (2018) 151(2):235-42. doi: 10.1016/j.ygyno.2018.08.022

118. Basaran D, Bruce S, Aviki EM, Mueller JJ, Broach VA, Cadoo K, et al. Sentinel Lymph Node Mapping Alone Compared to More Extensive Lymphadenectomy in Patients With Uterine Serous Carcinoma. Gynecol Oncol (2020) 156(1):70-6. doi: 10.1016/j.ygyno.2019.10.005

119. Schlappe BA, Weaver AL, McGree ME, Ducie J, Zahl Eriksson AG, Dowdy SC, et al. Multicenter Study Comparing Oncologic Outcomes After Lymph Node Assessment Via a Sentinel Lymph Node Algorithm Versus Comprehensive Pelvic and Paraaortic Lymphadenectomy in Patients With Serous and Clear Cell Endometrial Carcinoma. Gynecol Oncol (2020) 156 (1):62-9. doi: 10.1016/j.ygyno.2019.11.002

120. Nasioudis D, Albright BB, Roy A, Ko EM, Giuntoli RL 2nd, Haggerty AF, et al. Patterns of Use and Outcomes of Sentinel Lymph Node Mapping for Patients With High-Grade Endometrial Cancer. Gynecol Oncol (2020) 159 (3):732-6. doi: 10.1016/j.ygyno.2020.09.023

121. Bogani G, Papadia A, Buda A, Casarin J, Di Donato V, Gasparri ML, et al. Sentinel Node Mapping vs. Sentinel Node Mapping Plus Back-Up Lymphadenectomy in High-Risk Endometrial Cancer Patients: Results From a Multi-Institutional Study. Gynecol Oncol (2021) 161(1):122-129. doi: 10.1016/j.ygyno.2021.01.008

122. Nemani D, Mitra N, Guo M, Lin L. Assessing the Effects of Lymphadenectomy and Radiation Therapy in Patients With Uterine Carcinosarcoma: A SEER Analysis. Gynecol Oncol (2008) 111(1):82-8. doi: 10.1016/j.ygyno.2008.05.016

123. Koh WJ, Abu-Rustum NR, Bean S, Bradley K, Campos SM, Cho KR, et al. Uterine Neoplasms, Version 1.2018, NCCN Clinical Practice Guidelines in Oncology. J Natl Compr Cancer Network JNCCN (2018) 16(2):170-99. doi: 10.6004/jncen.2018.0006

124. Altin D, Taşkın S, Kahramanoglu I, et al. Combination of Sentinel Lymph Node Mapping and Uterine Frozen Section Examination to Reduce SideSpecific Lymphadenectomy Rate in Endometrial Cancer: A Turkish Gynecologic Oncology Group Study (TRSGO-SLN-002). Int J Gynecol Cancer (2020) 30(7):1005-11. doi: 10.1136/ijgc-2020-001353

125. National Comprehensive Cancer Network. NCCN) Clinical Practice Guidelines in Oncology. Uterine Neoplasms, Version 3. (2021) ENDO-C 2 of 6. Available at: https://www.nccn.org/professionals/physician_gls/pdf/ uterine.pdf. (Accessed June 03, 2021).

126. Renz M, Marjon N, Devereaux K, Raghavan S, Folkins AK, Karam A. Immediate Intraoperative Sentinel Lymph Node Analysis by Frozen Section is Predictive of Lymph Node Metastasis in Endometrial Cancer. J Robotic Surgery (2020) 14(1):35-40. doi: 10.1007/s11701-019-00928-z

127. Bellaminutti S, Bonollo M, Gasparri ML, Clivio L, Migliora P, Mazzucchelli $\mathrm{L}$, et al. Sentinel Lymph Node Intraoperative Analysis in Endometrial Cancer. J Cancer Res Clin Oncol (2020) 146(12):3199-205. doi: 10.1007/ s00432-020-03356-x

128. Casarin J, Multinu F, Abu-Rustum N, Cibula D, Cliby WA, Ghezzi F, et al. Factors Influencing the Adoption of the Sentinel Lymph Node Technique for Endometrial Cancer Staging: An International Survey of Gynecologic Oncologists. Int J Gynecol Cancer (2019) 29(1):60-7. doi: 10.1136/ijgc2018-000020

129. Renz M, Diver E, English D, Kidd E, Dorigo O, Karam A. Sentinel Lymph Node Biopsies in Endometrial Cancer: Practice Patterns Among Gynecologic Oncologists in the United States. J Minim Invasive Gynecol (2020) 27(2):4828. doi: 10.1016/j.jmig.2019.04.006

130. Bogani G, Mariani A, Paolini B, Ditto A, Raspagliesi F. Low-Volume Disease in Endometrial Cancer: The Role of Micrometastasis and Isolated Tumor Cells. Gynecol Oncol (2019) 153(3):670-5. doi: 10.1016/j.ygyno.2019.02.027

131. de Boer SM, Powell ME, Mileshkin L, Katsaros D, Bessette P, Haie-Meder C et al. Adjuvant Chemoradiotherapy Versus Radiotherapy Alone for Women With High-Risk Endometrial Cancer (PORTEC-3): Final Results of an 
International, Open-Label, Multicentre, Randomised, Phase 3 Trial. Lancet Oncol (2018) 19(3):295-309. doi: 10.1016/S1470-2045(18)30079-2

132. Schwartz GF, Giuliano AE, Veronesi U, Consensus Conference C. Proceedings of the Consensus Conference on the Role of Sentinel Lymph Node Biopsy in Carcinoma of the Breast, April 19-22, 2001, Philadelphia, Pennsylvania. Cancer (2002) 94(10):2542-51. doi: 10.1002/cncr.10539

133. Compton CC, SpringerLink ebooks MAmerican Joint Committee on C. AJCC Cancer Staging Atlas: A Companion to the Seventh Editions of the AJCC Cancer Staging Manual and Handbook. 2nd ed. New York: Springer (2012).

134. Kim CH, Soslow RA, Park KJ, Barber EL, Khoury-Collado F, Barlin JN, et al. Pathologic Ultrastaging Improves Micrometastasis Detection in Sentinel Lymph Nodes During Endometrial Cancer Staging. Int J Gynecol Cancer (2013) 23(5):964-70. doi: 10.1097/IGC.0b013e3182954da8

135. Euscher E, Sui D, Soliman P, Westin S, Ramalingam P, Bassett R, et al. Ultrastaging of Sentinel Lymph Nodes in Endometrial Carcinoma According to Use of 2 Different Methods. Int J Gynecol Pathol (2018) 37(3):242-51.doi: 10.1097/PGP.0000000000000415

136. Escalona S, Rezic M, López C, Medina F, Jurado J, Lobo J. Ultra-Staging of the Sentinel Lymph Node in Endometrial Cancer. Rev Venezolana Oncologia (2018) 30(2):83-97.

137. Naoura I, Canlorbe G, Bendifallah S, Ballester M, Darai E. Relevance of Sentinel Lymph Node Procedure for Patients With High-Risk Endometrial Cancer. Gynecol Oncol (2015) 136(1):60-4. doi: 10.1016/j.ygyno.2014.10.027

138. Touhami O, Trinh XB, Gregoire J, Sebastianelli A, Renaud MC, Grondin K, et al. Predictors of Non-Sentinel Lymph Node (Non-SLN) Metastasis in Patients With Sentinel Lymph Node (SLN) Metastasis in Endometrial Cancer. Gynecol Oncol (2015) 138(1):41-5. doi: 10.1016/j.ygyno.2015.04.008

139. Yabushita H, Shimazu M, Yamada H, Sawaguchi K, Noguchi M, Nakanishi $M$, et al. Occult Lymph Node Metastases Detected by Cytokeratin Immunohistochemistry Predict Recurrence in Node-Negative Endometrial Cancer. Gynecol Oncol (2001) 80(2):139-44. doi: 10.1006/gyno.2000.6067

140. Todo Y, Kato H, Okamoto K, Minobe S, Yamashiro K, Sakuragi N. Isolated Tumor Cells and Micrometastases in Regional Lymph Nodes in Stage I to II Endometrial Cancer. J Gynecol Oncol (2016) 27(1):e1. doi: 10.3802/jgo.2016.27.e1

141. Mueller JJ, Pedra Nobre S, Braxton K, Alektiar KM, Leitao MM Jr, Aghajanian C, et al. Incidence of Pelvic Lymph Node Metastasis Using Modern FIGO Staging and Sentinel Lymph Node Mapping With Ultrastaging in Surgically Staged Patients With Endometrioid and Serous Endometrial Carcinoma. Gynecol Oncol (2020) 157(3):619-23. doi: 10.1016/j.ygyno.2020.03.025

142. St Clair CM, Eriksson AG, Ducie JA, Jewell EL, Alektiar KM, Hensley ML, et al. Low-Volume Lymph Node Metastasis Discovered During Sentinel Lymph Node Mapping for Endometrial Carcinoma. Ann Surg Oncol (2016) 23(5):1653-9. doi: 10.1245/s10434-015-5040-z

143. Plante M, Stanleigh J, Renaud MC, Sebastianelli A, Grondin K, Gregoire J. Isolated Tumor Cells Identified by Sentinel Lymph Node Mapping in Endometrial Cancer: Does Adjuvant Treatment Matter? Gynecol Oncol (2017) 146(2):240-6. doi: 10.1016/j.ygyno.2017.05.024

144. Goebel EA, St Laurent JD, Nucci MR, Feltmate CM. Retrospective Detection of Isolated Tumor Cells by Immunohistochemistry in Sentinel Lymph Node Biopsy Performed for Endometrial Carcinoma: Is There Clinical Significance? Int J Gynecol Cancer (2020) 30(3):291-8. doi: 10.1136/ijgc2019-000934

145. Sawicki S, Kobierski J, Liro M, Wojtylak S, Lass P, Wydra D. [Micrometastases in Sentinel Lymph Node in Endometrial Cancer Patients]. Ginekologia polska (2015) 86(4):262-7. doi: 10.17772/gp/2071

146. Niikura H, Okamoto S, Yoshinaga K, Nagase S, Takano T, Ito K, et al. Detection of Micrometastases in the Sentinel Lymph Nodes of Patients With Endometrial Cancer. Gynecol Oncol (2007) 105(3):683-6. doi: 10.1016/ j.ygyno.2007.01.052

147. Raffone A, Travaglino A, Santoro A, Esposito I, Angelico G, Spadola S, et al. Accuracy of One-Step Nucleic Acid Amplification in Detecting Lymph Node Metastases in Endometrial Cancer. Pathol Oncol Res (2020) 26(4):2049-56. doi: 10.1007/s12253-019-00727-9

148. Fanfani F, Monterossi G, Di Meo ML, La Fera E, Dell'Orto F, Gioè A, et al. Standard Ultra-Staging Compared to One-Step Nucleic Acid Amplification for the Detection of Sentinel Lymph Node Metastasis in Endometrial Cancer Patients: A Retrospective Cohort Comparison. Int J Gynecol Cancer (2020) 30(3):372-7. doi: 10.1136/ijgc-2019-000937
149. Monterossi G, Buca D, Dinoi G, La Fera E, Zannoni GF, Spadola S, et al. Intra-Operative Assessment of Sentinel Lymph Node Status by One-Step Nucleic Acid Amplification Assay (OSNA) in Early Endometrial Cancer: A Prospective Study. Int J Gynecol Cancer (2019) 29(6):1016-20. doi: 10.1136/ ijgc-2018-000113

150. Kostun J, Pesta M, Slama J, Slunéćko R, Vlasák P, Bouda J, et al. One-Step Nucleic Acid Amplification vs Ultrastaging in the Detection of Sentinel Lymph Node Metastasis in Endometrial Cancer Patients. J Surg Oncol (2019) 119(3):361-9. doi: 10.1002/jso.25322

151. Tranoulis A, Georgiou D, Yap J, Attard-Montalto S, Twigg J, Elattar A, et al. The Evolving Role of One-Step Nucleic Acid Amplification (OSNA) for the Intra-Operative Detection of Lymph Node Metastases: A Diagnostic Accuracy Meta-Analysis. Eur J Surg Oncol J Eur Soc Surg Oncol Br Assoc Surg Oncol (2021) 47(6):1233-43. doi: 10.1016/j.ejso.2020.12.001

152. Stewart CJ, Crook ML, Lacey J, Louwen K. Cytokeratin 19 Expression in Normal Endometrium and in Low-Grade Endometrioid Adenocarcinoma of the Endometrium. Int J Gynecol Pathol (2011) 30(5):484-91. doi: 10.1097/ PGP.0b013e3182158944

153. Tamaki Y. One-Step Nucleic Acid Amplification (OSNA): Where Do We Go With it? Int J Clin Oncol (2017) 22(1):3-10. doi: 10.1007/s10147-016-1030-9

154. Hunter-Smith AE, Rayter Z. One-Step Nucleic Acid Amplification: The Possible Value in Assessing Sentinel Lymph Node Metastasis During Mastectomy. Breast Cancer (Dove Med Press) (2018) 10:13-21. doi: 10.2147/BCTT.S113737

155. Chiang AJ, Yu KJ, Chao KC, Teng NN. The Incidence of Isolated Para-Aortic Nodal Metastasis in Completely Staged Endometrial Cancer Patients. Gynecol Oncol (2011) 121(1):122-5. doi: 10.1016/j.ygyno.2010.11.026

156. Singh V, Chaudhary A, Modi KB, Singh LS, Roy L, Dougall P, et al. A Prospective Study of Role of Sentinel Lymph Node Biopsy in Low-Risk/ Intermediate-Risk Early-Stage Endometrial Carcinoma Using Dual-Dye and Dual-Site and Injection Technique. Indian J Gynecol Oncol (2019) 17(2). doi: 10.1007/s40944-019-0262-9

157. Kim YN, Eoh KJ, Lee JY, Nam EJ, Kim S, Kim YT, et al. Comparison of Outcomes Between the One-Step and Two-Step Sentinel Lymph Node Mapping Techniques in Endometrial Cancer. Int J Gynecol Cancer (2020) 30(3):318-24. doi: 10.1136/ijgc-2019-000962

158. Signorelli M, Crivellaro C, Buda A, Guerra L, Fruscio R, Elisei F, et al. Staging of High-Risk Endometrial Cancer With PET/CT and Sentinel Lymph Node Mapping. Clin Nucl Med (2015) 40(10):780-5. doi: 10.1097/ RLU.0000000000000852

159. Barlin JN, Zhou Q, St Clair CM, Iasonos A, Soslow RA, Alektiar KM, et al. Classification and Regression Tree (CART) Analysis of Endometrial Carcinoma: Seeing the Forest for the Trees. Gynecol Oncol (2013) 130 (3):452-6. doi: 10.1016/j.ygyno.2013.06.009

160. Altin D, Taskin S, Tokgozoglu N, Vatansever D, Guler AH, Gungor M, et al. Can Risk Groups Accurately Predict non-Sentinel Lymph Node Metastasis in Sentinel Lymph Node-Positive Endometrial Cancer Patients? A Turkish Gynecologic Oncology Group Study (Trsgo-Sln-004). J Surg Oncol (2021) 123(2):638-45. doi: 10.1002/jso.26310

161. Baiocchi G, Mantoan H, Gonçalves BT, Faloppa CC, Kumagai LY, BadiglianFilho L, et al. Size of Sentinel Node Metastasis Predicts Non-Sentinel Node Involvement in Endometrial Cancer. Ann Surg Oncol (2020) 27(5):1589-94. doi: 10.1245/s10434-019-08045-9

162. Taşkın S, Altin D, Vatansever D, Tokgozoglu N, Karabük E, Turan H, et al. Sentinel Lymph Node Biopsy in Early Stage Endometrial Cancer: A Turkish Gynecologic Oncology Group Study (TRSGO-SLN-001). Int J Gynecol Cancer (2020) 30(3):299-304. doi: 10.1136/ijgc-2019-000847

Conflict of Interest: The authors declare that the research was conducted in the absence of any commercial or financial relationships that could be construed as a potential conflict of interest.

Copyright (c) 2021 Zhai, Zhang, Cui and Wang. This is an open-access article distributed under the terms of the Creative Commons Attribution License (CC BY). The use, distribution or reproduction in other forums is permitted, provided the original author(s) and the copyright owner(s) are credited and that the original publication in this journal is cited, in accordance with accepted academic practice. No use, distribution or reproduction is permitted which does not comply with these terms. 